\title{
El uso de la entrevista en las ciencias sociales. \\ En defensa de la "entrevista etnográfica"1
}

\author{
The Use of Interviews in the Social Sciences. \\ In Defense of the "Ethnographic Interview"
}

\author{
Stéphane Beaud ${ }^{*}$ \\ Université de Poitiers
}

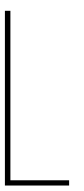

a crisis de los grandes modelos teóricos (marxismo, estructural-funcionalismo), el renovado interés por la labor de la escuela de Chicago, la importación de la etnometodología y el redescubrimiento del "sentido vivido de los actores” les devolvieron el sitio de honor durante los años setenta a los métodos de investigación llamados cualitativos, en particular, la biografía o "historia de vida"2. Sin embargo, la entrevista sociológica parece seguir siendo el pariente pobre de la reflexión “metodológica”,

Doctor en Sociología de la École des Hautes Études en Sciences Sociales (Ehess) y profesor de la Universidad de Poitiers. http://gresco.labo.univ-poitiers.fr/membres-du-laboratoire/membresa-titre-principal/beaud-stephane/.

1 Traducción del artículo de Stéphane Beaud "L'usage de l'entretien en sciences sociales. Plaidoyer pour l"entretien ethnographique'", publicado originalmente por la revista Politix, 9 (35): 226-257 en el año 1996. El Instituto Colombiano de Antropología e Historia agradece al autor y a la revista Politix por otorgar los permisos de reimpresión y traducción del artículo a la Revista Colombiana de Antropología.

2 En 1979, Yves Grafmeyer y Joseph Isaac tradujeron una recopilación de textos titulada L'école de Chicago (París: Champ Urbain, 1979). Para obtener información acerca de la biografía, consultar a Jean Peneff, La méthode biographique (París: A. Colin, 1994) y el artículo de Gaston Mauger "Mai 68 et la biographie", Les Cahiers de l'IHTP (1986). A raíz de esta rehabilitación a veces ambigua de lo "vivido", algunos sociólogos señalaron el riesgo de una regresión que se encuentra lejos del conocimiento del análisis relacional: fetichismo de microobjetos, olvido de las "estructuras" y descalificación a priori de toda investigación estadística. En registros diferentes, $c f$. Jean Claude Chamboredon, "Le temps de la biographie et les temps de l'histoire. Réflexions sur la périodisation à propos de deux études de cas", en Le sens de l'ordinaire, dir. Philippe Fritsch (París: CNRS, 1983); Daniel Bertaux "L’approche biographique: sa validité méthodologique, ses potentialités", Cahiers Internationaux de Sociologie LXIX (1980); Pierre Bourdieu "L'illusion biographique", Actes de la recherche en sciences sociales (1986): 62-63, y, además de diferentes explicaciones sobre este tema, Jean-Claude Passeron, "Le scénarioet le corpus. Biographies, flux, itinéraires, trajectoires", en Le raisonnement sociologique (París: Nathan, 1991). 
aunque la publicación en 1993 de La misère du monde ${ }^{3}$, bajo la dirección de Pierre Bourdieu (obra principalmente compuesta por una serie de entrevistas comentadas), generó un principio de discusión crítica, especialmente por parte de los politólogos ${ }^{4}$. Sin querer entrar en este debate, pretendemos contribuir con una aclaración sobre los usos de la entrevista sociológica a partir de un doble punto de vista: por una parte, haciendo hincapié en el análisis de las modalidades prácticas de la investigación ${ }^{5}$. Por otra parte, movilizando ampliamente material pedagógico exhaustivo acumulado sobre la entrevista en los últimos años curso de Métodos Cualitativos del Diploma de Estudios Universitarios Generales (DEUG), cursos del Diploma de los Estudios en Profundidad (DEA) - sobre la investigación directa y sobre la entrevista a profundidad, ya que estas situaciones concretas de aprendizaje del "oficio" son aquellas en las que incluso el maestro continúa aprendiendo sobre los diferentes tipos de obstáculos y resistencias que encuentran los estudiantes-aprendices de sociólogos.

Nadie ignora que analizar un instrumento de investigación como la entrevista hace que siempre se corra el riesgo de caer en la tentación del "metodologismo”, como si la complejidad del planteamiento de la investigación en sociología pudiera reducirse, como suelen hacer creer la mayoría de los manuales de métodos $^{6}$, a una sucesión bien ordenada de simples preceptos, parecidos a "fórmulas". Deseamos abordar de otra manera este asunto de la entrevista con el objetivo de luchar contra el tratamiento aislado del cual es a menudo objeto, para reinscribirla en el desarrollo real de cualquier investigación de campo.

Véase especialmente el capítulo "Comprendre".

4 Nonna Mayer, "L'entretien selon Pierre Bourdieu. Analyse critique de La misère du monde", Revue Française de Sociologie 36 (1995); Gérard Grunberg y Etienne Schweisguth, "Bourdieu et la misère. Une approche réductionniste”, Reuue Française de Science Politique 46, n. ${ }^{\circ}$ (1996).

5 A través de lo que Jean-Michel Chapoulie llama "el estudio empírico de las actividades de la investigación en sus aspectos más concretos", en "La seconde fondation de la sociologie française, les États-Unis et la classe ouvrière", Revue Française de Sociologie 32, n. 3 (1991): 321. Yo mismo hice numerosas entrevistas, como "sociólogo de campo", y frecuentemente me vi obligado a dirigir mi propia práctica investigativa hacia la ejemplificación de mis observaciones. No obstante, debo aclarar que la mayor parte de este conocimiento se lo debo al largo trabajo desarrollado con Michel Pialoux en el campo de Sochaux-Montbéliard, en especial, durante numerosas entrevistas realizadas con él en las que aprendí mucho; de mi experiencia en la enseñanza en colaboración con Florence Weber; de la investigación etnográfica desde hace seis años en el DEA de ciencias sociales (ENS/EHESS); de la práctica de campo del mismo DEA y de las discusiones con Alban Bensa. préhensif (París: Nathan, 1996), el cual aborda asuntos similares a los tratados aquí, pero que no hemos tenido tiempo para discutir. Véase también Jean-Claude Combessis, La méthode en sociologie (París: La Découverte, 1996). 


\section{Las distintas maneras de utilizar la entrevista en la investigación sociológica}

Un trabajo de tipo sociológico sobre los usos de la entrevista en las ciencias sociales, que se base en una investigación histórica sobre las prácticas de investigación en las ciencias sociales, sacaría inmediatamente a la luz el tema de las tradiciones disciplinarias y el de los diferentes usos que ha tenido la entrevista en sociología, psicología, ciencia política y antropología. Ese trabajo mostraría, en particular, las modalidades tanto prácticas como teóricas según las cuales este método de investigación, nacido y desarrollado en una disciplina - la psicología- - y en un país - Estados Unidos - se ha difundido o se ha trasladado a otras disciplinas y a otros países. Se podría hacer énfasis en las formas de apropiación y reinterpretación de la entrevista en las ciencias sociales en función de las tradiciones metodológicas de cada una de estas disciplinas y del estado del campo de las ciencias sociales propias de cada país. Se piensa, principalmente, en el hecho de que la difusión de la "técnica” — para retomar de manera temporal una expresión que será objeto de nuestra crítica- de la entrevista del campo de la psicología clínica al de la sociología se hizo conservando ampliamente lo que podría llamarse la inversión de la forma intelectual inicial. Es decir, la estandarización del instrumento de investigación: recopilación de “opiniones”, entrevistador neutral y objetivo, escucha flotante, psicologización de las relaciones, adaptabilidad de la técnica a cualquier situación, etc.

\section{La primacía del "criterio de método" estadístico}

No se puede reflexionar acerca del lugar que ocupa la entrevista en la sociología sin tener en cuenta tanto la jerarquía de los objetos legítimos de investigación como la jerarquía de los métodos de investigación sociológica (las cuales se superponen). Jean-Claude Passeron señala que,

[...] con el perfeccionamiento y la sistematización de las técnicas de observación y razonamiento, los “métodos”, en efecto, tendieron a lo largo del siglo XX a retransmitir los objetos en el doble rol de emblema e instrumento de autonomía de una disciplina. Debido a su transposición formal a cualquier objeto, el método se ha convertido rápidamente en el principal reto de las maniobras de los grandes batallones disciplinarios. Un método compromete el prestigio y la influencia de la disciplina con la que se identifica: símbolo de un derecho de nacimiento de la ciencia que lo ha hecho madurar, es al mismo tiempo el mejor vehículo de su 
expansionismo. Pensemos en todos los roles para los que se han prestado la "significancia y la representatividad estadísticas para la sociología”.7

Si nos referimos únicamente al periodo de la posguerra, existen dos razones principales que permiten dar cuenta de este predominio del criterio del método estadístico en la sociología francesa: por una parte, la imposición del modelo del survey research durante la etapa de institucionalización de la disciplina y, por otra parte, la muy acentuada ruptura entre la sociología y la etnología en Francia.

La institucionalización de la sociología francesa - que comienza con los inicios del Centro de Estudios Sociológicos (CES) ${ }^{8}$, continúa con la creación de la carrera de Sociología en 1958, el desarrollo de departamentos de Sociología en la universidad y la creación de las principales revistas de la disciplina en los años sesenta, para luego terminar a principios de los años setenta- coincidió con la polarización de la reflexión metodológica ${ }^{9}$ sobre la única investigación estadística y con la ausencia de verdaderos debates en torno a la utilización del método de la entrevista. Durante este periodo predomina, entre los sociólogos de la nueva generación, la voluntad de realizar investigaciones ${ }^{10}$, la "preocupación de basar la nueva disciplina en el método estadístico, instrumento fundacional y de legitimación del carácter científico de la sociología”"11. La corriente "empirista” de la sociología francesa importa, entonces, a través de Jean Stoetzel y con

7 Jean-Claude Passeron, “La constitution des sciences sociales”, Le Débat 90 (1996): 105.

8 El Centro de Estudios Sociológicos se fundó en 1945 como un laboratorio afiliado al Centro Nacional de la Investigación Científica (CNRS). [N. de la E.].

9 A diferencia de Estados Unidos, donde la conjunción de la tradición sociológica de la investigación de campo con lo que llamamos "la escuela de Chicago" y la implementación de una sociología basada en cuestionarios a partir de conversaciones exploratorias (en estrecha relación con la creación de empresas privadas de encuestas) generaron, desde la década de los cincuenta, una amplia literatura sobre el tema. En Francia, podemos citar el artículo de Liliane Kandel, "Réflexions sur l'usage de l'entretien, notamment non-directif, et sur les études d'opinion", Épistémologie Sociologique 13 (1972). Por ejemplo, es sorprendente que la Revue Française de Sociologie haya destinado, después de su creación, varios artículos metodológicos a cuestionarios, particularmente refiriéndose al problema de las preguntas "abiertas" o "cerradas", pero muy pocos artículos a la entrevista, a excepción de los dos de "politólogos", el de 1975 de Guy Michelat, "Sur l'utilisation de l'entretien non-directif en sociologie”, Revue Française de Sociologie 16 (1975), y la reseña de Nonna Mayer de La misère du monde, artículo citado.

10 El "método de las investigaciones", como lo llamaba casi que misteriosamente Lévy-Bruhl; incluso Gueorgui Gurvitch se enamora de la sociometría, convocada para actuar como contrafuego frente a las encuestas de opinión introducidas por Jean Stoetzel; cf. Johan Heilbron "Pionniers par défaut? Les débuts de la recherche au Centre d'Études Sociologiques (19461960)", Revue Française de Sociologie 32, n. 3 (1991). 
motivo de numerosas sesiones de investigadores del CES en Estados Unidos, el método de survey research (en honor a la corriente que se volvió dominante en la sociología estadounidense) que da lugar a numerosas discusiones sobre los problemas técnicos vinculados con él, como el muestreo, la construcción de las variables, la verificación de las hipótesis, las pruebas estadísticas. La investigación de campo, valorada durante un corto momento en una primera fase del trabajo del equipo de Georges Friedmann (1946-1950), ha sido marginada progresivamente, e incluso excluida, en beneficio de las investigaciones estadísticas que parecen más fiables sobre el tema de la "prueba" y de la "representatividad". Jean-Daniel Reynaud (catedrático, candidato a doctor en filosofía, por aquel entonces joven investigador en el CES con Friedmann) insiste sobre este tema en una entrevista con Jean-Michel Chapoulie:

Se hizo todo un trabajo alrededor del Centro de Estudios Sociológicos. Hubo un debate muy grande, muchos intercambios [...] El tema era la sociología empírica de los Estados Unidos, aunque este término no designa precisamente de qué se trataba, no hay duda de que lo fascinante era este modelo, un modelo donde se aportaban pruebas, se calculaba, se utilizaban métodos ampliamente inspirados en la psicología social [...] Teníamos una especie de paradigma de demostración: teníamos datos, datos cuantificables que podemos representar en forma de tabla de doble entrada y hay pruebas: este es el comienzo de los años cincuenta. ${ }^{12}$

Los investigadores que trabajaban mediante la observación participante no confiaban mucho en sus materiales, de modo que escribían poco, se censuraban, siempre tenían incertidumbre en cuanto a la validez de sus resultados de búsqueda (demasiado especializados, demasiado fragmentados), impresionados en el momento de las presentaciones de investigación por el despliegue de las pruebas estadísticas de sus colegas que trabajaban mediante cuestionario. El testimonio recogido por Jean-Michel Chapoulie de Jacqueline Frisch-Gauthier (profesora de letras, hija de trabajadores, joven investigadora en el CES a finales de los años cuarenta, con cuatro años de trabajo de investigación en una fábrica), resulta en este sentido particularmente elocuente:

Hubo algo que me molestó mucho, que hizo que no llegara hasta el final de mi enfoque [...]. Cuando hacía una presentación, siempre recibía las siguientes reflexiones: "Eso no es representativo", "pero puede tener un alcance generalizable” [...] y acabé por inhibirme, por lo que preparé una serie de cosas, pero no sabía cómo darles un alcance general - por supuesto que se limitaba a una fábrica-, era mi sentimiento propio el 
que hacía que tuviera la impresión de que esto iba más allá, pero no salí de este impase. ${ }^{13}$

Luego abandona el método de observación participante para realizar estudios que se basan en el uso del enfoque "científico".

A partir de este periodo puede decirse que la investigación etnográfica se sitúa en la parte baja de la jerarquía de los métodos de investigación, como bien lo han demostrado los trabajos recientes de Jean-Michel Chapoulie y Jean Peneff: la estricta división del trabajo en la producción de la investigación científica en sociología se adecuaba a las jerarquías escolares, sexuales y sociales que funcionan mediante las siguientes parejas de oposiciones: teóricos / empiristasinvestigadores; hombres/mujeres; sociólogos provenientes de sectores burgueses / populares; parisinos/provinciales. Los entrevistadores de campo eran en su mayoría servidores humildes de los "profesores"14, como señalaba también Edgar Morin en 1966: "La entrevista suele ser una forma de vida subalterna, un oficio de apoyo para las mujeres desocupadas o en dificultades, un paso para los futuros investigadores. Es la tarea inferior de la que se descargan los jefes de equipo"15.

Por último, la segunda razón de este “impensado de la entrevista” está vinculada con la relación que sostiene en Francia la sociología con la tradición etnológica. Esta, a raíz de los trabajos de Malinowski, se constituyó haciendo del “campo” etnográfico el criterio del método antropológico, imponiendo la idea de que el trabajo de campo se caracteriza sobre todo por el método de la observación participante, método de inmersión en el terreno que por sí solo permite aprovechar lo que Malinowski llama los “imponderables de la vida social”. Por una parte, la ruptura institucional entre la sociología y la etnología ha sido durante mucho tiempo fuerte en Francia, a pesar del legado de Mauss, de modo que la circulación de los métodos de investigación entre las dos disciplinas ha sido

Chapoulie, "La seconde fondation", 354.

Si en ese entonces existía una libertad formal de los investigadores, en particular con respecto al objeto y a la orientación de su investigación, Johan Heilbron trae a memoria una restricción esencial: "Había que respetar la división del trabajo, según la cual los 'grandes' interrogantes, teóricos y de otro tipo, estaban reservados a los profesores. Esta distribución del trabajo, tan marcada en las actitudes y las expectativas recíprocas, reforzó la distinción entre los trabajos 'teóricos' y 'empíricos', lo cual caracterizó a la sociología de la posguerra inmediata" (Johan Heilbron, "Pionniers par défaut? Les débuts de la recherche au Centre d'Études Sociologiques [1946-1960]", art. citado, 371). 
limitada ${ }^{16}$. Por otra parte, cabe señalar que, en la tradición etnológica francesa, el etnógrafo es el principal encargado de llevarle los materiales al etnólogo, cuya función es teorizar. La etnografía se sitúa de esta manera en lo más bajo de la jerarquía interna de la disciplina (sin duda en relación con su pasado ${ }^{17}$ ). Por lo tanto, el trabajo de campo, en sus distintas fases poco descritas y analizadas, fue por mucho tiempo una especie de impensado, como si el hecho mismo de ser un campo exótico con sus limitaciones propias (aprendizaje de la lengua indígena, cambio de ambiente, malas experiencias del etnólogo en su campo) excusara de describir con detalle la manera de hacer trabajo de campo in situ. Por ejemplo, la entrevista no es en sí misma objeto de un análisis específico, oculto por la experiencia del campo y la ventaja de la situación de alteridad.

Se podría decir, finalmente, que la entrevista, como instrumento de investigación, ha estado atenazada durante un largo tiempo, "acorralada" entre la fuerte legitimidad de la instrumentación estadística en la sociología y la de la observación participante en la etnología (metropolitana), las cuales funcionan como emblema metodológico de sus respectivas disciplinas. Además, los contactos originarios y “culpables", si se permite decirlo, de la entrevista con la psicología (estadounidense) y, por lo tanto, con una forma de psicologismo, generan una fuerte sospecha de subjetivismo por parte de los sociólogos. Consecuencia inmediata: la entrevista se reduce a no ser más que un instrumento de investigación (delegado a los que tengan un "buen contacto"), una simple "técnica" sobre la cual no se reflexiona y que, al ser rutinaria, "funciona” de igual manera. Diversos criterios institucionales señalan esta posición subordinada de la investigación de campo (calificada falsamente de "cualitativa") en la sociología francesa, del pasado y contemporánea: debilidad en la literatura especializada sobre el tema - a diferencia de Estados Unidos-, la ausencia de una revista de sociología “cualitativa” (como existen muchas en Estados Unidos), una ubicación débil otorgada a las investigaciones etnográficas en revistas científicas de la disciplina (Revue Française de Sociologie, L'Année Sociologique, Cahiers Internationaux de Sociologie y, en menor medida, Sociologie du Travail) o en las revistas relacionadas con las instituciones (Travail et Emploi, Formation-Emploi), el número adicional de pruebas exigidas al fieldworker por los "lectores anónimos" durante la presentación de sus resultados en estas mismas revistas, resistencias múltiples a conceder un lugar a las "descripciones" o a las calificaciones etnográficas que

16 Con excepción de Chombart de Lauwe, exalumno de Mauss, quien posiblemente es el único etnólogo de formación que repatrió en sociología el método de la observación directa.

17 En Francia, en los años treinta, son los geógrafos herederos de Vidal de la Blache y los folcloristas quienes "van al campo de acción". 
parecen estar siempre bajo la amenaza de una supresión por parte del editor -no son lo suficientemente "científicas", parecen innecesarias a los profanos (“esto es demasiado detalle”) y recortan el "verdadero" texto (“teórico”) — y falta de puestos académicos identificados con esta etiqueta en la sección de sociología ${ }^{18}$. Tantos son los indicios convergentes que atestiguan el menor crédito científico concedido al trabajo etnográfico y que señalan la fuerte resistencia del mundo profesional de los sociólogos a considerar la entrevista sociológica (y la observación) como un instrumento de investigación tan científico — tan "noble”-, que los datos estadísticos que funcionan lo hacen, seguramente, como instrumentos de prueba.

\section{El implícito cuantitativo del trabajo mediante entrevistas}

Antes de abordar directamente los efectos sobre el trabajo mediante entrevistas por la dominación del criterio del método estadístico en la sociología francesa de la posguerra, conviene aclarar los malentendidos relacionados con la taxonomía de las investigaciones sociológicas. La división entre métodos “cuantitativos” y “cualitativos” (fuertemente institucionalizada en las enseñanzas universitarias) es, en gran medida, una falsa oposición ${ }^{19}$; sin embargo, tiene como objetivo homogeneizar artificialmente el ámbito de los estudios denominados “cualitativos”, y más concretamente el de las investigaciones “mediante entrevistas”. Esta misma distinción confiere una unidad metodológica a los trabajos que se caracterizan más bien por una muy fuerte diversidad en la manera de realizar y abordar las entrevistas. El examen detallado de los distintos tipos de entrevista sociológica requeriría de un trabajo de mucho esfuerzo; por tanto, nos limitaremos a plantear algunas hipótesis (provisionales) de la investigación sobre este tema.

"En el criterio del método (el derecho de definir y de enseñar el método adecuado) se da a conocer la mejor arma en las manos de las jerarquías académicas para quienes el control de una enseñanza es, en primer lugar, clave en sus actividades de contratación de un gremio, público o liberal", cf. Jean-Claude Passeron, Le raisonnement sociologique, 105. Por un lado, esta situación incierta de la entrevista en la investigación se traduce concretamente en las modalidades de formación en esta última. Por otro lado, solo al observar el procedimiento de reclutamiento universitario en sociología se pone de manifiesto la diferencia entre el número en aumento de "jóvenes investigadores de campo" y la falta de empleos correspondientes a esta especialidad. Habría que estudiar detalladamente la "asignación" de empleos en sociología y reflexionar acerca de esta ausencia.

Cf. François Héran, "Sociologie de l'éducation et sociologie de l'enquête: réflexions sur le modèle universaliste”, Revue Française de Sociologie 32, n. 3 (1991): 457-491, y Florence Weber, "L'ethnographie armée par les statistiques", Enquête 1 (1995): 153-165. 
El uso más generalizado de la entrevista consiste en reunir un número "representativo" de entrevistas, esta vez grabadas, para tratar temas específicos (las razones del voto por el Frente Nacional, la vida en pareja, etc.). La forma privilegiada de tratar la masa de información consiste, a partir de este material cualitativo que se podría llamar "cuantitativizado", en construir una tipología basada en el análisis extensivo de la diversidad de las entrevistas. Esta concepción dominante de la entrevista sociológica plantea un triple problema.

En primer lugar, las “jornadas” de entrevistas están diseñadas principalmente como una manera rápida de obtener una masa de información (de “datos”) y funcionan como un sustituto de las investigaciones mediante cuestionarios (más engorrosas de administrar y también más costosas). La división del trabajo científico y la jerarquización de las tareas son fuertes: los entrevistadores o los estudiantes se desplazan a campo llevando consigo una guía de entrevista y de consignas entregada por los directores de la investigación. El riesgo inherente de esta forma de administrar las entrevistas es la "mala interpretación”, provocada por la disociación entre el entrevistador y el intérprete que priva al entrevistadorintérprete de datos de control arrojados, por ejemplo, mediante el análisis de la situación de la entrevista.

En segundo lugar, este método de investigación establece una ruptura muy clara entre el trabajo mediante la entrevista, por un lado, y la observación, por el otro; además, el contexto de la entrevista está ausente en gran medida, el escenario de la interacción rara vez se describe, de modo que la única homogeneidad de los datos recopilados es la del "texto" resultante de las entrevistas, después de la transcripción de las grabaciones. A falta de datos sobre el contexto, en particular el contexto de lo dicho por los distintos hablantes, una de las inclinaciones posibles de interpretación es la de la producción de datos cuantificados sobre las entrevistas.

Por último, la lógica de producción de los datos y de las interpretaciones estará sometida a lo que Jean-Claude Passeron llama el "cuantitativo vergonzoso". Las investigaciones llamadas "cualitativas" se limitan muy a menudo a un número significativo de entrevistas que se hacen en condiciones y en momentos diferentes, con personas elegidas al azar. En este marco, las entrevistas solo tienen como unidad el planteamiento mismo de la entrevista y la grabación; no están conectadas entre sí por un campo o por un contexto comunes. El trabajo interpretativo tiene como fuente - además de las diversas fuentes de documentación escrita- el único "texto" de las diferentes entrevistas, con lo que desaparece la dimensión de la palabra de las investigaciones, la traducción de una lengua a otra, lo que compromete todo trabajo de tipo etnológico. La dispersión 
y el aislamiento de los datos producidos de esta forma obligan constantemente al sociólogo a hacer un razonamiento en "igualdad de condiciones" con el fin de neutralizar los efectos del contexto. El riesgo que se corre con este tipo de investigación es la producción de artefactos que basan el trabajo interpretativo en entrevistas ampliamente descontextualizadas: estas entrevistas se utilizan como "pedacitos de prueba" mientras que los datos esenciales de control de la entrevista -en particular la relación entrevistador/entrevistado, las características objetivas detalladas de la investigación - no siempre se mencionan. El trabajo comparativo permite, sin duda, un incremento de generalidad, pero sobre una base que sigue siendo en gran medida frágil y, de cualquier modo, debilitada. ¿Qué se compara cuando se analizan diversas entrevistas como textos? ¿Qué es lo que puede servir de base para el principio de variación? Existen situaciones y palabras, y finalmente se construye un texto uniendo los extremos de las entrevistas recortadas de su contexto de enunciación. La entrevista, utilizada de esta forma, adquiere un carácter puramente ilustrativo, prueba por defecto y sustituto frágil de una buena investigación estadística.

Finalmente, cabe preguntarse si el criterio de método estadístico que define a la sociología como disciplina no se ha impuesto, de una manera generalmente inconsciente, a los entrevistadores que adoptan una perspectiva de sociología "cualitativa”, quienes se han sometido en cierta forma a esta norma implícita de validez de los resultados de la investigación ${ }^{20}$. Los entrevistadores sienten como si estuvieran obligados a multiplicar el número de entrevistas, como si fuera necesario, en este ámbito, “hacer volumen”. Tal vez existe solo una mínima razón de orden puramente científico como prenda de conformidad para darle a la ciencia "normal" (en el sentido de Kuhn) una especie de aprobación metodológica al trabajo de tipo estadístico en la sociología. Tampoco se debe olvidar el papel que desempeñan las diversas instituciones que gestionan los contratos de investigación. Estas tienden a hacer prevalecer, más o menos abiertamente, el criterio de "volumen" en el ámbito de las investigaciones cualitativas, como lo demuestra,

Por ejemplo, esto se difunde, de forma más o menos inconsciente, alrededor de los estudiantes cuyos directores de tesis les exigen bastantes entrevistas, y quienes por lo tanto se encuentran a sí mismos obsesionados por la búsqueda de las entrevistas que deben realizar. La experiencia pedagógica, adquirida durante los marcos informales de trabajos de estudiantes del DEA (con frecuencia principiantes en investigación en esta etapa de su carrera, ya que muchos vienen de otras disciplinas - ciencias políticas, historia, economía-), muestra que varios estudiantes de sociología siempre tienen temor de no hacer lo suficiente, y al hacer demasiado, acumulan entrevistas de manera desordenada que enseguida se afanan a transcribir sin dedicar el tiempo necesario para trabajarlas con profundidad, para reflexionar sobre la construcción del objeto y la reelaboración progresiva de la problemática de partida. La realización de entrevistas se asemeja entonces a lo que Yves Winkin llama "aspiradoras de datos" (retomando una de las expresiones favoritas de Birdwhistell). Yves Winkin, Anthropologie de la communication: de la théorie au terrain (Bruselas: Universidad de Boeck, 1996). 
por ejemplo, la fuerte presión para que aparezca un elevado número de entrevistas en los proyectos de investigación, prenda de cientificidad o de "representatividad" de la investigación. Del mismo modo, las instituciones sospechan o descalifican las investigaciones basadas principalmente en monografías o en estudios de caso $^{21}$.

De este modo podemos detectar esta especie de ley metodológica no escrita en el "paratexto" de los trabajos de los sociólogos, especialmente en los anexos metodológicos de los artículos de revista o tesis y, sobre todo, en los debates colectivos sobre los trabajos (sustentaciones de tesis, comisiones del CNRS) durante los cuales se transmiten de forma implícita las normas metodológicas del trabajo científico en la disciplina. Para que un trabajo de tipo cualitativo sea denominado sociológico y se diferencie de un simple trabajo etnológico, todo transcurre como si el trabajo basado principalmente en un compendio de entrevistas debiera imperativamente comprender, o más bien exhibir, un elevado número de entrevistas ( $\mathrm{N}=50$ pero, mejor aún, $\mathrm{N}=100$, e incluso $>100)$.

\section{Asumir el carácter "no representativo" de la entrevista}

¿Cómo hacer para que, en las investigaciones a través de entrevistas, la administración de la prueba no acabe por basarse, en última instancia, en un razonamiento de tipo cuantitativo en el que se le ha hecho desempeñar a la entrevista el único papel de proveer datos cuantificables? ¿Cómo evitar entonces el uso inhabitual de la entrevista a profundidad o subutilizarla? Se defiende la idea de que la fuerza heurística de la entrevista sociológica se aferra tanto — siempre que se inscriba en una investigación etnográfica que le dé un marco de referencia y le proporcione puntos de referencia y comparación-a su singularidad que el sociólogo puede operar como caso límite de análisis, que le confiere un poder de generalidad. Restringir el trabajo intensivo a un número muy limitado de entrevistas es de alguna manera confiar en las posibilidades de este instrumento de investigación, en especial, es una forma de mostrar la coherencia de las actitudes

21 Durante la presentación de un contrato de investigación en respuesta a una licitación del Ministerio de Educación Nacional, nuestro proyecto de investigación, el cual estaba basado en la comparación de dos investigaciones de campo en dos vecindarios de desarrollo social (DSQ) de Montbéliard (entre los que se encuentra el "suburbio" parisino de L'Usine-Genevilliers), fue preseleccionado pero finalmente no fue escogido. Buscando conocer de forma legítima las razones, pudimos obtener, con mucha dificultad, como simple explicación que nuestro proyecto era "demasiado etnográfico". 
y conductas sociales, inscribiéndolas en una historia o una trayectoria tanto personal como colectiva.

La inscripción de un trabajo realizado con entrevistas en el marco de una investigación etnográfica, es decir, el objetivo de realizar entrevistas en profundidad - al cual llamamos entrevistas etnográficas - que sean consagradas en la investigación de campo (asumida por su ritmo, su ambiente), permite liberarse del yugo del pensamiento estadístico o, más precisamente, de la especie de superego cuantitativo que induce al entrevistador a multiplicar el número de sus entrevistas. Las entrevistas se llevan a cabo naturalmente dentro de una lógica de investigación. Este enfoque progresivo del campo también conduce a hacer preselecciones y elecciones de entrevistas posibles. La investigación etnográfica nos enseña con rapidez que cualquier persona social no es "entrevistable”, que existen condiciones sociales en la toma de palabra.

Por ejemplo, deseoso al comienzo de realizar entrevistas a jóvenes desempleados que residían en un barrio de viviendas de interés social, cerca de la fábrica de Sochaux (donde me había instalado en un apartamento durante el verano de 1990), me di cuenta bastante rápido de que mi empresa estaba abocada al fracaso: los contactos no daban resultado, las promesas de entrevista que había logrado conseguir nunca se cumplían, por lo que me encontraba tres semanas después del inicio sin ningún resultado concreto (una buena entrevista grabada). Al mismo tiempo, el grupo era cerrado, no había espacio abierto, el trabajo de observación era difícilmente realizable en esta época del año y en el plazo que me habían asignado. De ahí que surgiera la idea de superar estas dificultades buscando otro ángulo de ataque, realizando una investigación por observación participante en la agencia de empleos donde encontraría jóvenes con las mismas características sociales, pero que estaban, esta vez, en la obligación institucional de hablar ${ }^{22}$. Durante mi investigación de campo realizada entre 1989 y 1993-1994, me resultaría imposible recordar cuántas entrevistas realicé; algunas (pocas) no han sido grabadas, un número considerable no se han vuelto a transcribir, o muy parcialmente, porque me parecían informativas, menos importantes para “profundizar” que otras. En cambio, a medida que la investigación avanzaba, es decir, que la problemática se afirmaba y que las hipótesis de investigación se consolidaban, seleccioné un pequeño número de entrevistas en profundidad (un poco más de una veintena) que personalmente volví a transcribir, siempre en su totalidad. Son estas las entrevistas en las que he trabajado intensamente, tratando de imprimirles a fondo un modo de razonamiento sociológico. Lo que 
me lleva a pensar que la primera ilusión de la que un entrevistador -yo mismo he sido víctima- debe deshacerse es la del número de entrevistas.

Tuve que realizar y grabar una docena de entrevistas en profundidad sobre la relación de las familias en el colegio, apoyándome principalmente en la red local de la Asociación de Padres de Alumnos de colegios en Zonas de Educación Prioritaria. No pude o no quise explotarlas todas ya que, por una parte, había una gran redundancia de los temas abordados y, por otra, preferí centrar mi esfuerzo de transcripción e interpretación en dos largas entrevistas particularmente ricas con una familia de trabajadores ${ }^{23}$. Estas dos entrevistas realizadas con un año de intervalo arrojan lo que el análisis estadístico no permite aclarar: los procesos de enlace singulares ${ }^{24}$, el estrecho vínculo de temas disociados (el colegio, el barrio, la relación a futuro, el futuro de los niños, el de sí mismo). Otro ejemplo: en una serie de entrevistas con alumnos de origen popular, progresivamente centré mi atención en el paso del colegio de un barrio periférico de interés social al colegio del centro de la ciudad en el momento de entrar a la secundaria, haciendo una serie de entrevistas sobre este único tema, seleccionando preguntas que me surgieron a lo largo del camino, pertinentes y significativas: posición espacial en la clase, relación con el maestro, forma de pedir la palabra en clase, tipo de ocupación del espacio dentro del colegio, ritmos temporales (restaurante o regreso a casa), modo de constitución de redes de amigos. De esta manera, analicé ampliamente una muy rica entrevista con una niña del barrio que vio cómo su universo se derrumbaba al pasar a la secundaria ${ }^{25}$.

Cf. Stéphane Beaud "L'école et le quartier. Des parents ouvriers désorientés", Critiques Sociales 5, n. ${ }^{\circ} 6$ (1994): 13-46.

La entrevista tuvo lugar en su casa, durante las vacaciones de Todos los Santos, cuando todavía se encontraba conmocionada por su llegada a la secundaria: pérdida de los puntos de referencia espaciales y temporales, separación de sus antiguas amigas, aislamiento en su clase, temor de no estar a la altura académicamente (me lo confesó) o socialmente (es lo que dice entre líneas). No deja de repetir "estamos traumatizadas" a lo largo de la entrevista para evocar el choque cultural sufrido al frecuentar, en el transcurso de estos primeros meses, el liceo "burgués". El relato de Kelkal presenta sorprendentes similitudes con lo que pude obtener en Sochaux-Montbéliard. Es cuando sale del entorno protegido del barrio y del colegio de Vaux-en-Velin (donde era "buen" estudiante) para entrar al liceo de Lyon (en el séptimo distrito) que se encuentra "perdido" y chocándose con los prejuicios sociales. 


\section{La entrevista y la investigación etnográfica}

La cuestión que plantea el uso de la entrevista en ciencias sociales consiste menos, me parece, en establecer nuevas tipologías de entrevistas que en llegar a apreciar el valor relativo de ajuste de un instrumento de investigación a un objeto o a una fase del conocimiento. Es decir, hay que poder evaluar, gradualmente, el camino durante una investigación y la validez provisional de las distintas técnicas de investigación a disposición del sociólogo. El punto de vista que se defiende aquí es que la entrevista a profundidad se beneficia de ser utilizada en el marco de una investigación etnográfica cuyo método preferido es la observación participante (“estar con”, "hacer con”, estar "sumergido” en el medio investigado, secreto de los mejores trabajos etnográficos $\left.{ }^{26}\right)$. Sin embargo, hay que recordar, en una primera etapa, contra toda forma de exclusivismo e imperialismo metodológico, que la entrevista a profundidad en la investigación etnográfica es más comúnmente usada como una segunda opción, una manera de obtener información y puntos de vista sobre un objeto del que no se pueden recopilar materialmente in situ mediante observación directa. Es el caso, por ejemplo, de los trabajos sobre las instituciones en las que a menudo es difícil instalarse como entrevistador (las cárceles, las fábricas ${ }^{27}$, etc.). Las entrevistas largas, a veces

Cf. Florence Weber, Le travail à côté. (París: Ehess-INRA, 1989); Olivier Schwartz, "L'empirisme irreductible", epílogo de Nels Anderson. Le Hobo (París: Nathan, 1993). Tal y como lo señala Yves Winkin en los consejos que prodiga a sus estudiantes antes de enviarlos al campo de acción: "aquellos estudiantes a los que les propongo este método de trabajo, en apariencia sumamente exigente, a menudo intentan evadirlo al llevar con ellos una grabadora, una cámara fotográfica o a veces una cámara de video. Siempre los animo a no hacerlo. El trabajo de observación debe hacerse en primer lugar a simple vista, las notas deben tomarse con un poco de prisa en el lugar y las reescrituras largas en la bitácora, y en la noche frente a la chimenea [...] Solo es hasta mucho más tarde, cuando se encuentre bien acomodado en su sitio de trabajo, que eventualmente podrá registrar sus datos. R. Birdwistell, formado en los años cuarenta en el Departamento de Antropología de la Universidad de Chicago, fue quien me entrenó en este tipo de trabajo etnográfico en la Universidad de Pensilvania en los años setenta. No quería que trabajáramos con una cámara porque decía que eso era ser, por retomar sus dos expresiones, unas veces como una aspiradora -recolectamos la información sin saber a qué aspiramos, tenemos una bolsa llena, y la abrimos y no sabemos qué hacer con todo eso- y otras veces como un preservativo: ustedes se protegen contra el peligro, se sienten cómodos detrás de la cámara; esto es una manera de no estar cara a cara con la otra persona y eso pone en riesgo su área de trabajo", Yves Winkin, Anthropologie de la communication: de la théorie au terrain, 112.

Podemos citar el trabajo de Antoinette Chauvenet, Georges Benguigui y Françoise Orlic acerca de los guardias de prisión y el trabajo que dirige Michel Pialoux en la fábrica de Sochaux desde 1983. Sin embargo, este último tuvo cuidado en definir su ámbito, de centrar su trabajo primero que todo en la fábrica de guarnición (por lo tanto, hizo una serie de entrevistas pormenorizadas con Christian Corouge, OS [operario] en su taller), luego en los talleres llamados de "acabado" de la planta de carrocería y, finalmente, en la nueva fábrica de HC1 [HabillageCaisses], cuando los operarios fueron transferidos allá entre 1989 y 1990. Este largo trabajo basado en una multiplicidad de entrevistas (con los operarios, calificados y no calificados, 
repetidas con las personas que trabajan dentro, sirven de datos de sustitución que, no obstante, pueden ser muy ricos si se sabe compartir con el entrevistado el deseo de conocimiento del entrevistador, haciendo que se vincule a una especie de pacto de entrevista(s) basado en una suerte de trabajo común (como es el caso de un trabajo de tipo biográfico).

\section{La entrevista como situación de observación}

La experiencia de la investigación demuestra que una entrevista a profundidad solo tiene sentido realmente dentro de un "contexto", en función del lugar y del momento de la entrevista ${ }^{28}$. La situación de entrevista es, por sí sola, una escena de observación, más exactamente, solo la observación de la escena social (lugares y personas) que constituye la entrevista proporciona elementos para su interpretación.

En las entrevistas que pude realizar con padres obreros o sus hijos estudiantes que vivían en un barrio muy degradado de la región de SochauxMontbéliard, la observación de los lugares — cuando me dejaban acceder a los apartamentos 29 - demostraba claramente cómo los habitantes de estos edificios en mal estado, objeto de promesas eternas de remodelación, intentaban mediante la distribución de su espacio interior poner distancia con la "ciudad" (la "podredumbre" del mundo exterior): la limpieza de los apartamentos contrastaba con la suciedad de las escaleras; el aspecto nuevo de los papeles tapiz, con la pintura descascarada y los revestimientos de las paredes decrépitas; el sonido del

jóvenes y viejos, hombres y mujeres, campesinos y citadinos, franceses e inmigrantes, pero también con supervisores, fueran "monitores", jefes de equipo o contramaestres) le permitió acumular un gran conocimiento tanto de la fábrica - acerca de métodos de producción y de cambios del trabajo obrero, de la vida social y sindical de estos talleres- como de lo que ocurre "fuera de ella" (barrio, escuela, vida política local, etc.), lo cual le dio sentido al trabajo de entrevistas que después pudimos realizar juntos. No obstante, es seguro que, en la mayoría de los casos, nada reemplaza la riqueza de la observación directa, siempre y cuando el sociólogo sepa abrirse a otros puntos de vista diferentes del de la observación "aquí y ahora".

Por ejemplo, en la serie de entrevistas realizadas por Michel Pialoux a Christian Corouge, él muestra que el discurso que mantuvo con este obrero especializado cambiaba significativamente de acuerdo con el momento en que la entrevista tuvo lugar (inmediatamente después del trabajo en la fábrica, en la víspera anterior a la reanudación de labores el día lunes, justo después de un incidente en los talleres). Cf. Chronique Peugeot, Actes de la recherche en sciences sociales, 52-53, 54, 57, 60, (1984, 1985).

29 Me di cuenta de que, durante la mayoría de mis entrevistas con estudiantes de secundaria que tuvieron lugar fuera de sus casas (en un parque público en el verano, en un café o en un lugar para jóvenes), ya que me ocultaban cuidadosamente el lugar donde vivían, me pedían, por ejemplo, que los llevara en carro hasta la plaza del centro comercial y luego ellos caminaban hasta su domicilio. 
chorrito de agua que corría de la fuente miniatura instalada en la entrada de la sala contrastaba con la estridencia de los gritos de los niños en el exterior. Todo parecía concebido para recrear, en el interior, un mundo silencioso, tranquilo y pacífico.

En un reciente artículo ${ }^{30}$, Michel Pialoux pone de manifiesto que solo el análisis detallado del contexto de la entrevista -las dificultades desde el contacto telefónico inicial hasta el relato-análisis de las diferentes fases del desarrollo de la entrevista, pasando por la observación de las actitudes, gestos, ruidos, tanto en el intercambio cara a cara como fuera del escenario propio de la entrevista- permite brindarles todo el sentido a los propósitos que las investigaciones les confieren a las entrevistas. En una investigación (realizada con Dominique Baillet, estudiante de DEA) sobre los padres de alumnos de un barrio de interés social de una pequeña ciudad del centro de Francia, experimentamos las mayores dificultades, debido a la inexistencia de una asociación de padres de familia, para encontrar un "contacto" y comenzar una primera entrevista. Al pedirle a la oficina postal contigua al primer piso de uno de los edificios del barrio que nos indicara quién podría aceptar reunirse con nosotros, obtuvimos algunos apellidos de las familias del barrio que le parecían idóneas. Nos dirigimos a una de ellas; un niño de aproximadamente diez años nos respondió (sus padres estaban ausentes, “donde el médico con la pequeña”) y nos invitó a volver al iniciar la tarde. Cuando volvimos a las dos de la tarde, un niño que nos observaba a través de la mirilla les gritó con júbilo a sus padres: “¡Son los estudiantes! ¡Son los estudiantes!”. Este es un momento importante, nos estaban esperando, nos sirvieron café inmediatamente, toda la familia se reunió en torno a los dos estudiantes, la entrevista se prolonga, las compras tradicionales del sábado por la tarde en el supermercado se aplazarán dos horas. La entrevista tiene lugar en el comedor en torno a la mesa, el padre y la madre ${ }^{31}$ sentados frente a nosotros, los cuatro hijos forman un círculo alrededor de nosotros y participan a veces de la conversación, y traen por turnos sus cuadernos o sus libros cada vez que sus padres tratan de convencernos de la veracidad de sus afirmaciones, como pruebas materiales auténticas de buena voluntad de "padres de alumnos" y su buena fe. La entrevista

30 Michel Pialoux, "L'ouvrière et le chef d'équipe ou comment parler du travai?", Travail et Emploi 62 (1995): 4-39.

El padre, de 35 años de edad, trabaja como obrero de mantenimiento en una compañía de refacción de apartamentos de vivienda de alquiler moderado. La madre trabaja en el hogar desde el inicio de su matrimonio. La pareja tiene cinco hijos, el mayor tiene doce y la menor, un año. Los cuatro hijos, que están estudiando en escuelas primarias del barrio, encuentran casi todas las dificultades escolares significativas - especialmente el tercero, cuyo caso es evocado de inmediato y del que no se sabe si tiene dos o tres años de retraso-. 
se cierra con la visita guiada del apartamento, donde nos muestran las habitaciones de los niños: por un lado, la "habitación de los juguetes" y la habitación con camas (dos camas superpuestas en la misma habitación). Toda la familia participa en la entrevista, lo que hará que sea difícil de transcribir; las palabras de unos y otros se superponen; el padre y la madre a menudo hablan al entrevistador que está frente a ellos, como si cada uno tuviera mucho que decir sobre (y contra) el colegio (y los “coles"), y como si cada uno quisiera convencer a su interlocutor del fundamento de sus críticas. La entrevista cobra todo su sentido solo en el contexto; esta familia, muy movilizada escolarmente y ya enfrentada a los fracasos de los hijos mayores, espera de parte de los estudiantes que seamos una ayuda directa, al menos una alianza temporal contra sus enemigos estructurales - profesoras, trabajadores sociales, psicólogos escolares-que quisieran trasladar sobre sí mismos como padres la culpa del fracaso escolar de sus hijos. Solo el análisis detallado del contexto de la entrevista y el análisis de la relación que establece entre entrevistadores y entrevistados permiten comprender el significado sociológico, mientras que el texto mismo de la entrevista - entrecortado, incoherente, a veces incomprensible o abstruso-será poco utilizable.

Es evidente que el trabajo de análisis e interpretación de una entrevista a profundidad comienza mucho antes de la propia grabación de la cinta. Las condiciones para el establecimiento de la relación de investigación son esenciales para devolver, si se quiere objetivar la relación entrevistador/entrevistado y comprender el desarrollo de la entrevista. Puede decirse, sin exagerar, que los primeros momentos del encuentro son estratégicos: marcan un clima, una "atmósfera" en la cual se desarrollará a continuación la entrevista.

\section{Diferentes tipos de entrevistas según los medios sociales}

La entrevista sociológica, lejos de limitarse a una simple comunicación cara a cara entre A y B (como lo postula toda una tradición de la entrevista a partir de la psicología social), es también una relación social entre dos personas que se diferencian por sus características sociales, académicas y sexuales. Es una relación de poder, como lo demuestran, en particular, los retos sobre la negociación del lugar y momento de la entrevista. Se sabe, por ejemplo, que las investigaciones con cierto poder social tienen más tendencia a querer imponer el lugar -como su oficina "espléndida" y beneficiarse del prestigio asociado a ella-y a fijar (limitar) la duración de la entrevista, mientras fingen seguirle plenamente el juego a esta. Investigar en las zonas "burguesas” se asemeja, con frecuencia, al sociólogo 
percibido como un intelectual de condición social inferior, a aprobar un examen final en el cual debe hacer sus pruebas de "corrección” y "entrevista”32.

En algunos círculos profesionales (alta administración, empresariado), hay que ser capaz de “imponerse a los imponentes”. Cuando estos últimos imponen demasiado, especialmente cuando se enfrentan a estudiantes principiantes en el oficio y a los que no se privan de afirmarles su fuerza social ${ }^{33}$, se puede dudar del poder de objetivación de la entrevista y preguntarse si un trabajo de observación participante no es el más adecuado.

Durante la enseñanza sobre la entrevista en profundidad con Florence Weber en el DEA, hallamos, con algunos estudiantes que trabajaban en el mundo empresarial, una fuerte resistencia a cumplir una serie de reglas inherentes al desarrollo de una entrevista en profundidad: la necesidad de realizar entrevistas que sean largas y grabadas, que no sean cerradas sino abiertas a diferentes aspectos de la realidad social, que también deban realizarse fuera del marco de trabajo, si es posible en el domicilio de los entrevistados. Estos estudiantes, a menudo "practicantes" en esas mismas empresas que eran sus lugares de investigación, querían, a cualquier precio, realizar entrevistas con los directivos, en ese entonces, sus compañeros de trabajo. Las entrevistas ocurrieron naturalmente en el lugar de trabajo y, por supuesto, los entrevistadores se enfrentaban con regularidad a entrevistas recalcitrantes, en las que "colegas amigables” se convertían repentinamente en entrevistados difíciles, rígidos, poco conversadores. Las entrevistas rara vez sobrepasaron los 30 o 45 minutos y durante este periodo limitado no se pudo obtener dato alguno sobre el ámbito "fuera de trabajo" (familia, origen social, destinos académicos y profesionales de los hermanos). Algunos de sus estudiantes estaban conformes, puesto que aportaban "informaciones" provenientes de allí mismo, donde una jornada regular de trabajo de campo habría bastado ampliamente y habría sido muy pertinente. Existe un gran riesgo de aplicar a la fuerza técnicas de investigación a objetos que se resisten a ellas con firmeza.

32 Cf. Michel Pinçon y Monique Pinçon-Charlot, "Pratiques d'enquête dans l'aristocratie et la grande bourgeoisie: distance sociale et conditions spécifiques de l'entretien semi-directif", Genèses 3, n. 1 (1991): 120-133.

Cf. Hélène Chamboredon, Fabienne Pavis, Muriel Surdez y Laurent Willemez, "S'imposer aux imposants", Genèses 16, n. 1 (1994): 114-132. No cabe duda de que la situación es diferente cuando las personas entrevistadas se enfrentan a sociólogos profesionales, más maduros, que no se dejan intimidar fácilmente. A veces podemos cuestionarnos acerca de la necesidad de hacer caer en cuenta a los estudiantes denominados "analistas políticos" acerca de las entrevistas que ocurren en condiciones difíciles, de vez en cuando imposibles, al confrontarlos directamente con los políticos que los manipulan a su manera sometiéndolos con su poder. 
En segundo lugar, se les aconseja con frecuencia a los entrevistadores "principiantes" comenzar por preparar una guía de entrevista para hacer entrevistas dirigidas o semiestructuradas. Si la consigna de "preparar" la conducción de una entrevista no es en sí cuestionable, la presencia de una guía puede tranquilizar al entrevistador (con su lista de preguntas sobre la mesa), no obstante, la guía de entrevista puede cambiar la relación de investigación. En particular, le confiere un carácter oficial y casi académico a la situación de entrevista que hace que se asemeje a aprobar un examen. Resulta que el modo de utilización de la guía - y los efectos que ejerce sobre la situación de la entrevista- no son objeto de debate entre los profesionales ${ }^{34}$. Son cuestiones que se perciben como puramente "técnicas". Sin embargo, en la práctica, es evidente que la utilización de una guía de entrevista modifica la relación entre entrevistador y entrevistado de manera diferenciada, según las características académicas y sociales de los entrevistados.

Cuando estos últimos tienen un determinado capital cultural o social, la guía de entrevista puede surgir como una patente de seriedad y competencia y mitigar así las sospechas que no pueden dejar de influir sobre esta "bestia social” extraña que es ante sus ojos un sociólogo. Como identificación profesional del entrevistador, ennoblece la relación de investigación y contribuye a que la interacción se desarrolle según un marco acordado, cercano a una situación natural del modelo de la conversación "burguesa". En todo caso, la guía de entrevista confiere a las investigaciones una posición valorada de persona competente que responde a las preguntas del sociólogo. El uso de la guía de entrevista plantea en cambio otros problemas para el caso de las entrevistas en medios populares ${ }^{35}$. Se corre un gran riesgo de aumentar la distancia social entre el entrevistador y el

Ya había evocado esta pregunta en el transcurso de una discusión crítica del artículo de Bernard Lahire. Stéphane Beaud, "Quelques observations relatives au texte de B. Lahire", Critiques Sociales 8 (1996).

Aquí puedo evocar un recuerdo personal de las entrevistas "dirigidas" realizadas durante una investigación en el Instituto de Investigaciones Económicas y Sociales (IRES), en el marco de un contrato de investigación financiado por el Ministerio de la Investigación y la Tecnología junto con la Agencia Nacional para el Mejoramiento de las Condiciones de Trabajo (ANACT) sobre la "negociación sindical de las nuevas tecnologías". La concepción demasiado intervencionista por parte de nuestros financiadores, que ante todo deseaban resultados de investigación conformes a esta forma de negociación colectiva que querían imponer a los "asociados sociales" (quienes, si los hubiéramos escuchado, habrían reducido a poca cosa el trabajo de investigación), hizo que literalmente nos impusieran una guía para hacer entrevistas muy cuadriculada y casi absurda (cinco páginas mecanografiadas con una serie de preguntas muy precisas). Por lo tanto, la conmoción causada era violenta para los sindicalistas ya que su mensaje era quebrantado; al seguir ciegamente nuestra guía para hacer entrevistas, les llevábamos la contraria a nuestros interlocutores y "rompíamos" por completo la relación en la investigación, y terminábamos por "sabotear" las entrevistas que hubieran podido ser muy significativas. 
entrevistado, reforzando el mecanismo de asignación social de este por parte de la escritura, o más exactamente, de la cultura escrita y de la cultura legítima. Por lo tanto, el verdadero trabajo de refuerzo de la confianza que el entrevistador hace a lo largo de la entrevista se torna más difícil.

La utilización de una guía de entrevista “ajustada” sitúa a nuestros interlocutores en la posición de "dar respuesta" a una serie limitada de preguntas, que les puede parecer rápidamente repetitiva como lo demuestran, por momentos, las miradas furtivas e inquietas a la guía, temiendo que aún haya muchas otras preguntas. Sobre todo, frena en seco toda posibilidad de liberación de palabra por parte de la entrevista; sin embargo, una de las competencias más seguras de la entrevista etnográfica, "no dirigida", consiste precisamente en la posibilidad que ofrece de concatenar las ideas, de hacer fluir al locutor según su inclinación (al menos en una primera instancia), mediante el libre juego de las asociaciones de ideas (el parentesco con la sesión de psicoanálisis es evidente), lo que requiere por parte del entrevistador una gran disponibilidad de escucha. No obstante, la sucesión de preguntas impide que se desencadene una dinámica de la entrevista que, si se realiza, termina por hacer que se parezca a una conversación "sin pies ni cabeza”.

Además, la guía frente a la mirada del entrevistador aumenta las posibilidades de percibir la entrevista como una simple serie de preguntas, a veces de tipo académico, a la que el entrevistado, para “quedar bien”, intentará ajustarse: dando una serie de respuestas breves y sin profundidad, en espera sin cesar de las siguientes preguntas del sociólogo, no dejándose llevar, como si estuviera limitado por el “cuestionario”. Esta configuración es más probable, máxime si esta representación del intercambio se hace sobre el modo de la asimilación de la entrevista al "sondeo". Cuántas veces se oye decir, en el momento de solicitar una entrevista: "sí, es para responder a una encuesta”, "debo responder a sus preguntas, ¿cierto?”. Una de las primeras tareas del entrevistador es luchar contra esta representación de la entrevista, recurriendo a circunlocuciones o artificios ("no es exactamente eso, se le preguntará por su punto de vista”...), con el objetivo de tranquilizar a los encuestados sobre cómo será la entrevista. Muy a menudo los entrevistadores deben luchar contra la imagen negativa que pueden tener de sí mismos, la cual les impide considerarse en un primer momento como posibles "buenos" interlocutores ("usted sabe, yo no tengo nada que decir", "sugiero que vaya a ver a tal persona, él le informará mejor que yo" o "hablar así no es mi fuerte”, "vamos a intentarlo, se dará cuenta de lo que producirá y lo que podrá sacar", y desde los primeros momentos de la entrevista, la advertencia: "provengo de origen humilde”, etc.), representación de sí mismos que está directamente 
relacionada con su experiencia académica ("no he estudiado mucho", "nunca fui un estudiante sobresaliente") y de la cual se liberan en parte los portavoces de las clases populares (elegidos políticos, delegados sindicales, militantes asociativos, etc.). De alguna manera, una gran parte del trabajo del entrevistador consiste en anular o hacer olvidar el sentimiento de desvalorización de sí mismo que se puede experimentar durante las entrevistas, lo que haría de ellos, $a$ priori, locutores "imperfectos". Hay que asegurarse de que estos últimos sientan progresivamente que tienen derecho a expresarse, para lograr a lo largo de la entrevista investigaciones totalmente legítimas, sin que duden de si deben hablar ampliamente sobre sus experiencias personales, en términos de lenguaje común. El desarrollo de la entrevista lo demuestra bien porque hay diferencias significativas de registro de lenguaje entre el comienzo - en el que el entrevistado se acomoda al nivel oficial del lenguaje, tomando prestado para la ocasión el "código elaborado" ${ }^{36}$ de los dominantes-y la mitad o el final de la entrevista, en el que el entrevistado, ya en confianza, se deja llevar progresivamente y recupera su registro común de lenguaje (“código restringido"). Hay que reconocer que esta variación del registro de lenguaje durante la entrevista, esencial para la interpretación, va acompañada frecuentemente por el entrevistador que puede emitir mil señales de connivencia y comprensión (aprobación de la mirada, estímulo verbal o no verbal para continuar, compartir emociones en el momento, etc.) para facilitar esta transición lenta.

En resumen, todas ellas son razones a favor para no siempre recargarse a la hora de utilizar una guía de entrevista, lo que no impide, por supuesto, escribir en un papel los temas para no olvidarlos.

\section{Conducir una entrevista: obtener datos y relatos de prácticas}

Para llevar a cabo una entrevista etnográfica hay que poder recopilar datos objetivos para controlar los datos subjetivos y obtener numerosas anécdotas. Una entrevista etnográfica debe dotarse de medios de objetivación. Ya se ha visto que el marco de la entrevista es en sí mismo un medio de objetivación, pero la entrevista es capaz, por sí sola, de producir un conjunto de datos a la vez objetivos y subjetivos. Como señala Bernard Zarca:

[...] es preciso distinguir lo que se dice durante una entrevista, los hechos objetivos (por ejemplo, el hecho de haber sido aprendiz de tal oficio, 
durante tal periodo, etc.) y los juicios sobre los hechos ("era duro, el patrón era muy severo") que constituyen datos que, a falta de algo mejor, pueden llamarse "subjetivos" y que informan igualmente sobre la subjetividad presente del locutor y sobre su pasado necesariamente reconstruido. Por lo tanto, hay que analizar estos "datos subjetivos" refiriéndolos a todo el camino sociolaboral del individuo: la valoración de las condiciones difíciles de aprendizaje puede ser muy diferente, en la madurez, según el camino que se haya recorrido. ${ }^{37}$

La posesión de un cierto número de datos objetivos es indispensable si se quiere poner después en relación estos últimos (recopilados de manera dispersa a lo largo de la entrevista) con los puntos de vista subjetivos manifestados por el entrevistado. Este enfoque no es el único medio del que dispone el sociólogo para interpretar una entrevista. Mediante una paradoja que es solo aparente, se trata, finalmente, de reproducir sobre un material etnográfico, “cualitativo”, el precepto durkheimiano que ordena al sociólogo "explicar lo social por lo social”, o extraer todas las implicaciones de la sociología interaccionista de Goffman. Si nos situamos al nivel de la entrevista en sí misma, se trata de objetivar al entrevistado como persona social en el curso mismo de la entrevista mediante el aprovechamiento de todas las indicaciones corporales, de lenguaje, escénicas que señalan algunos rasgos de su identidad social. Por supuesto, esta búsqueda se hace camino durante la entrevista, sin preocuparse por la formalización, en el marco de los distintos temas abordados, a discreción del juego natural de preguntas sucesivas, preocupándose por recopilar información pertinente sobre sus principales características sociales o culturales en el nivel más detallado que sea (historia familiar del lado paterno y materno, trayectoria académica, profesional, residencial, filiaciones políticas y religiosas, etc.).

Una de las principales dificultades prácticas que encuentra todo "entrevistador” es la tendencia de las entrevistas a querer tomar altura, a entregar un “testimonio" de alcance general, de un "buen nivel”, adaptándose de esa forma a lo que perciben como las expectativas del entrevistador. Esta actitud de las entrevistas varía, por supuesto, según los medios sociales, y tiende a ser más frecuente cuando el nivel de recursos sociales y culturales es elevado.

Durante una investigación mediante entrevistas realizadas entre profesores de enseñanza secundaria ${ }^{38}$, se advierte que estos manifiestan una fuerte

37 Bernard Zarca, Les artisans. Gens de métier, gens de parole (París: L'Harmattan, 1987), 9.

38 Investigación colectiva realizada en el marco de la preparación de una sesión de críticas sociales. Cf. Stéphane Beaud y Florence Weber, "Des professeurs et leurs métiers face à la démocratisation des lycées”, Critiques Sociales 3, n. 4 (1992): 59-122. 
reticencia a hablar de las prácticas profesionales más banales de su profesión. Espontáneamente, tienden más a evocar temas "intelectuales" - en términos de pedagogía, psicología (del niño o del adolescente) e incluso sociología- que a hablar en detalle sobre las actividades cotidianas de su profesión: dirigirse a los alumnos, hablar en clase, guardar silencio, establecer una cierta atmósfera de trabajo, recompensar, amonestar o sancionar a los alumnos, corregir tareas, calificar a los alumnos (por escrito y oralmente), en resumen, todo lo que puede considerarse desde su punto de vista como los aspectos poco gratificantes (y sin embargo esenciales) de la profesión. Hacen falta, entonces, una intervención activa del sociólogo y el establecimiento de un clima de confianza para lograr que los entrevistados reflexionen sobre sus propias prácticas. Desde el principio, los entrevistados asimilan la situación de la entrevista como una discusión entre "intelectuales" que no es muy diferente a aquellas que forman la trama de la sociabilidad común de profesores de secundaria. Esta definición de la situación excluye, por lo tanto, hablar de cosas tan poco importantes y materiales como las condiciones laborales o la remuneración de los maestros. Este mismo comportamiento también se da entre los portavoces autorizados, como los militantes políticos o sindicales que - efecto de aculturación vinculado a los diferentes mecanismos de aprendizaje de las actividades militantes y a su inclinación social ascendente- tienden a desarrollar discursos en un lenguaje de préstamos, extraído del registro de las lecturas sindicales, palabras que funcionan como auténticos discursos pantalla de las prácticas sociales concretas ${ }^{39}$.

¿Por qué la anécdota es uno de los puntos de apoyo más poderosos de la entrevista etnográfica? Por una parte, es un relato más o menos corto de una situación social vivida que permite situar inmediatamente la entrevista del lado de las prácticas sociales vigentes en el medio investigado, haciendo revivir una escena social donde se dejan ver, a menudo en detalle, varias de esas prácticas (lo que es más, facilitando el tránsito del locutor hacia un estilo directo ${ }^{40}$ mediante un diálogo fielmente recordado). Por otra parte, dada su aparente banalidad y su carácter sin importancia (“usted sabe, es solo una anécdota”), la anécdota autoriza al entrevistado para que hable de los fenómenos de contenido profundamente sociológico, sin temor a infringir las buenas costumbres y, por tanto, a decir con toda sencillez, e incluso con toda la ingenuidad, cosas que prohíbe la censura

En el transcurso de la misma investigación en IRES, yo había establecido, paso a paso, como estrategia de investigación interrogar principalmente a los delegados del personal, los más cercanos a la "base" y a la vida en los talleres.

40 Cf. "La crítica del estilo indirecto" de Claude Grignon y Jean-Claude Passeron, en Le savant et le populaire (París: Gallimard-Seuil, 1989). 
social común. En este sentido, la anécdota es un formidable revelador y analizador de situaciones sociales y el arte del entrevistador consiste en saberlas suscitar abundantemente, en el momento adecuado y en consonancia con el discurso del entrevistado.

La anécdota tiene otra virtud importante desde el punto de vista del desarrollo de la entrevista. Le permite al entrevistador comprender rápidamente los pormenores de una situación social, tomar caminos durante la entrevista. Con frecuencia, el relato resultante lleva al entrevistador a que se precisen los elementos de la escena relatada (los actores, el lugar, el ambiente, las palabras pronunciadas, las actitudes de los participantes, etc.); la escena es fuente de nuevas preguntas-hipótesis y permite una mejor reactivación.

Entre otros ejemplos de anécdotas, se podría tomar el de la entrevista (realizada con Olivier Masclet en el marco de una investigación sobre los trabajadores de una empresa de neumáticos durante la práctica de campo del posgrado en ciencias sociales) con Lucette P., trabajadora jubilada, exdelegada sindical de la Confederación General del Trabajo (CGT) de su sector en la fábrica, quien se convirtió en la principal responsable de la $\mathrm{CNL}^{41}$ del barrio de interés social donde vive desde hace treinta años. La entrevista, que fue larga (tres horas y media), giró en torno a los diferentes temas estrechamente entrelazados en su existencia: el trabajo en la fábrica, el sindicalismo, el barrio, la familia, etc. A lo largo de su relato aparece de forma omnipresente la figura "combatiente" de Lucette, la preocupación por la "lucha”, la lucha para “defenderse”. Hacia el final de la entrevista, Lucette evoca en detalle una anécdota que parece definir mejor el sentido de su existencia y su personalidad, de la misma manera que ilustra la defensa colectiva de un grupo y de un barrio. Es la historia de la lucha que contribuyó a llevar a cabo en contra del supermercado vecino, único proveedor de pan desde la desaparición de la panadería, para hacer que dejara de vender pan “malo". Punta de lanza del combate, Lucette nos narra cómo llevó a cabo con su familia la batalla del pan: movilizando a toda su red familiar (todos sus hermanos que viven en los edificios vecinos, cada uno de ellos se releva por la mañana para salir en su auto a buscar el pan al centro de la ciudad), motivando a su vecindad y su red a boicotear el nuevo pan del supermercado. Finalmente, la "lucha" dio fruto; Lucette y sus amigos se salieron con la suya: la producción de un mejor pan en el supermercado de la ciudad, haciendo de esta forma que volviera una parte de sus antiguos clientes. Anécdota, sí, pero cuán significativa sobre la complejidad de las esferas sociales (familia, barrio, política, relación con 
el dinero) y de las luchas infrapolíticas que constituyen la forma que adquiere la politización en sectores populares ${ }^{42}$.

\section{El mito de la neutralidad del entrevistador}

La presentación de las entrevistas como una "técnica” de investigación pone de relieve una concepción normativa de la entrevista en la que su desarrollo debería obedecer a una suerte de orden formal impecable, como si fuera necesario a cualquier precio borrar los imponderables, las dificultades del entrevistador para estabilizar la interacción (dificultades relacionadas directamente con el carácter propiamente social de la situación de la entrevista), como si también existiera una forma única de hacer una entrevista. Sin embargo, el entrevistador puede realizar muy buenas entrevistas en profundidad (en el plano de los resultados de la investigación), siendo torpe, cometiendo "errores", equivocándose en el momento o mostrándose a veces demasiado intervencionista. Las "buenas" entrevistas están menos relacionadas con las cualidades técnicas "abstractas" que con la capacidad del entrevistador para generar y obtener -incluso de manera torpe o mediante la violación de las consignas "técnicas"- la confianza del entrevistado que, por sí sola, conducirá a la recopilación de un material suficientemente rico para ser interpretado. Lo mismo cabe interrogarse sobre la postura de escucha aconsejada para llevar a cabo una entrevista no dirigida ${ }^{43}$ : el entrevistador benevolente, atento, neutral, "ayuda" al entrevistado, cuyas palabras se reducen a la expresión de sus propias "opiniones”.

Sin embargo, la "neutralidad" del entrevistador es un mito que es muy difícil de cambiar, ya que durante una entrevista el sociólogo suele ser invitado para que dé su opinión, a veces para consolidar el punto de vista de su interlocutor. Con much frecuencia no puede eludir las diversas formas discretas de la conminación del entrevistado; dar su aprobación constituye, al menos en un primer momento, la única manera de continuar el intercambio que funciona como una especie de combustible para la entrevista. El móvil de la entrevista radica precisamente en

42 Sobre esta cuestión se puede mencionar la serie de "Chroniques Peugeot" citada en Michel Pialoux, "Alcool et politique dans l'atelier. Une usine de carrosserie dans la décennie des années quatrevingt", Genèses 7, n. 1 (1992): 94-128; Olivier Schwartz, "Sur le rapport des ouvriers du Nord à la politique. Matériaux lacunaires”, Politix 4, n. 13 (1991): 79-86.

43 "A partir de una pregunta inicial lo suficientemente amplia y al adoptar una postura de escucha neutra pero no pasiva, a diferencia de lo que afirma Pierre Bourdieu, el investigador ayuda al entrevistado a desarrollar sus opiniones a su manera, dentro del marco de la visión del mundo que le resulte apropiada", Gérard Grunberg y Etienne Schweisguth, "Bourdieu et la misère. Une approche réductionniste", art. citado. 
la capacidad que tenga el entrevistador de encontrar buenos ángulos de ataque, de suscitar la confianza del entrevistado, dando consentimiento a palabras que a veces pueden ser chocantes como persona privada o como ciudadano.

Si bien es natural dejar en un primer momento que la persona entrevistada desarrolle, más o menos, su punto de vista de manera amplia, que avance a su ritmo, "siga su camino" - haciendo uso de toda una serie de expresiones para hacer comprender que el entrevistado sigue lo que Goffman llama una "línea de acción”-, siempre llegará un momento de la entrevista en el que el entrevistador debe "recuperar la mano", profundizar en los temas, aclarar las cosas que no quedaron claras, hacer decir lo que previamente se dijo a media palabra, volver sobre o aclarar las contradicciones que pudo detectar en las observaciones de las entrevistas, y contribuir así a arrojar luz sobre una serie de hechos pasados por alto o que se mantuvieron en penumbras. El entrevistador no deja pues de ser "activo" (y protagonista), aunque solo sea por su comportamiento no verbal de cara a cara: por gestos de aprobación, de sorpresa, de compasión, de estupefacción. En resumen, el entrevistador dispone de una paleta de medios verbales y no verbales para gestionar la distancia y la proximidad con el entrevistado. Puede por momentos acercarse físicamente a su interlocutor, como para escucharlo mejor y prestar una atención más fina a sus palabras, o por el contrario retroceder en su silla o sillón como para alejarse y marcar una distancia con el entrevistado; en este sentido, el modelo de análisis aplicado por Goffman a las escenas de la vida diaria debería aplicarse en la entrevista etnográfica. El sociólogo, experto en entrevistas, sabrá desempeñar plenamente este juego de la distancia y la proximidad pudiendo manifestar a su vez sentimientos de sorpresa, de falsa ingenuidad, de verdadera compasión y de sincera empatía. El arte del sociólogo reside en su capacidad de adaptarse a la situación, a la persona, de ganarse su simpatía. La "neutralidad” del entrevistador es un señuelo metodológico que tiene una parte relacionada con algún tipo de ideología profesional (de los sociólogos), ya que permite exhibir el principio de "neutralidad axiológica", tótem protector y emblema de identificación de la disciplina, esgrimida si llegase el caso contra los sociólogos que no la respeten.

Contra el punto de vista "metodologista" que plantea una serie de fórmulas para "triunfar" en una entrevista (como se "logra” un buen plato), cabe recordar que una relación de entrevista se construye de extremo a extremo, desde el primer contacto, y que se refleja en todo momento. A partir de algunos indicios, obtenidos por observación o en los primeros intercambios, el entrevistador debe saber, como en un juego social de pistas, situarse sobre el buen camino, detectar rápidamente los temas que "funcionan", que permiten comenzar la entrevista 
sobre los asuntos que tocan de cerca su existencia social. La realización de una entrevista no deja de poner en juego y de generar interpretaciones por parte del entrevistador que está obligado a hacer “en caliente”. En este sentido, la entrevista etnográfica exige un trabajo constante y detallado de escucha ${ }^{44}$ : el entrevistador, al acecho, como un cazador, listo para detectar el menor indicio, la menor información "sociológica" — de tipo verbal, pero también no verbal, como los muchos silencios, vacilaciones, suspiros y diversas formas de mímica que suplen o acompañan a las palabras del entrevistado-, que registra y que utiliza según el caso para hacer avanzar su entrevista sobre la persona social de la investigación. De esta manera, el sociólogo acumula a lo largo de la entrevista una serie de indicadores sociales objetivos e indicios subjetivos y puede empezar a hacer, abrir camino a una serie de aproximaciones "socio-lógicas", a prever futuros resultados y así evaluar la probabilidad de respuestas a algunas de sus preguntas. Puede, incluso, una vez asegurada una serie de logros de la entrevista, sugerir interpretaciones a sus interlocutores que se muestren de acuerdo, o que a veces discrepen e impulsen de esta forma el “debate”.

\section{El aprendizaje de la entrevista: las lecciones de la resistencia a la sociología}

En materia de aprendizaje de campo, solo se puede compartir la concepción del enfoque etnográfico propuesta por Yves Winkin a sus estudiantes:

¿Cómo lograr que el estudiante abandone el calor de su hogar, de su estudio o de su biblioteca para ir a campo, enfrentarse a lo desconocido, a “informantes” burlones y a la pregunta “¿Qué es lo que hago aquí?” [...]. Una respuesta es segura: no sirve de mucho hacerle leer un manual de metodología cualitativa. Más vale hablar de sus propias inquietudes, sus propios ensayos y errores. Más vale empezar por algo pequeño: un pequeño campo (el café es el ejemplo paradigmático), algunas ideas prestadas de Goffman de la presentación de sí mismo, algunos esquemas. Y poco a poco la confianza llegará. ${ }^{45}$

44 No es una casualidad si siempre salimos fatigados, o incluso a veces agotados, de una entre vista exhaustiva. Lo anterior no se debe tanto a la duración sino a la propia entrevista (incluso si algunas pueden durar tres o cuatro horas seguidas) y al estrés asociado a la necesidad de volver a contactar al encuestado a conveniencia. Se les recomienda a los estudiantes que no las multipliquen (una al día sería lo ideal).

Yves Winkin, Anthropologie de la communication: de la théorie au terrain, 101. Otra forma de iniciarse en la práctica consiste en leer entrevistas comentadas, siempre y cuando estas sean 
Esto no significa, sin embargo, la abdicación de toda posibilidad de enseñanza en este ámbito. No obstante, la lectura de los manuales de método suele ser decepcionante porque no se encuentran respuestas a cuestiones prácticas de la investigación. Esta impresión de desfase viene del hecho de que las fórmulas que se presentan son desencarnadas, las recomendaciones, abstractas: no le permiten al estudiante imaginar cómo puede conducir y prepararse para una entrevista y sobre todo prepararse mentalmente para esa situación social, a la vez banal e intimidante, cara a cara entre el entrevistador y el entrevistado. Solo se disecciona la técnica, ninguna atención se concederá al contexto, la relación entrevistador/entrevistado se aborda muy poco o desaparece. Lo que sigue siendo olvidado en la pedagogía de la entrevista, y que sería seguramente una contribución a la sociología de la sociología, son las dificultades prácticas de elaboración y de establecimiento y estabilización de la relación de investigación, las “trampas” que todo entrevistador encuentra en campo, las situaciones de incomodidad mental y malestar que puedan ocurrir, las mismas que tienen el efecto de desalentar a los estudiantes que se inician en la investigación directa y que están descubriendo este aspecto del campo (generalmente relegadas en las notas de investigación del “entrevistador” o enterradas en su memoria).

Uno de los primeros problemas que hay que plantear es esta especie de idea recibida, transmitida por los mismos que han aprendido la sociología "sobre la marcha”, según la cual la entrevista no sería susceptible de una enseñanza metódica, que respondería solamente a lo que podría llamarse el "olfato" sociológico del entrevistador. Se encuentra incluso en algunos antropólogos esta concepción “idealista” del oficio. Enseñar las técnicas de la investigación en campo, en una relación maestro-compañero como en una práctica, por ejemplo, estaría cerca de la herejía profesional y constituiría una desviación de la búsqueda iniciática y solitaria del etnólogo de campo, que se experimenta en la investigación en contacto con el Otro. El aprendizaje colectivo y explícito del “campo” podría hacer perder a este último su "misterio". Sin embargo, las experiencias de "práctica de iniciación a la antropología” demuestran, por el contrario, la necesidad de una pedagogía activa y controlada de la entrevista. Nada es más sorprendente

presentadas íntegramente, aquellas que adquirieron, de forma reciente, un verdadero estatus de texto sociológico. Una de las consecuencias del predominio del criterio cuantitativo del método fue una especie de descalificación científica de los trabajos o de los textos basados en la entrevista. Se sabe que uno de los actos de fuerza "teórico-metodológicos" de la revista Actes de la Recherche en Sciences Sociales fue el de publicar unos artículos basados en la presentación y transcripción de entrevistas, y de contribuir de esta forma, en parte, a legitimarlos en la disciplina. Es la primera revista sociológica, al menos en Francia, que le da credibilidad a la entrevista sociológica. Cabe mencionar las entrevistas analizadas y comentadas por Michel Pialoux, Abdelmalek Sayad y Bernard Zarca. 
que la cuasi vanidad de los consejos que se dan en clases sobre la entrevista en profundidad (anterior al inicio de la práctica), sobre la manera de realizar una entrevista; al ver a los estudiantes en acción, se advierte que han olvidado todo, o casi todo, de la enseñanza didáctica, y que lo esencial se juega en su capacidad, socialmente constituida, para entrar en relación con el entrevistado, para hacer que comprenda su proyecto de trabajo, para establecer esta relación social de tipo particular que es la situación de investigación. Acompañar a los estudiantes en una entrevista es ver inmediatamente lo que los aprendices-estudiantes ven y lo que no ven en la situación de entrevista. Lo que se percibe sobre todo en estas prácticas de campo es que no hay nada menos natural que realizar una entrevista y esbozar a continuación un trabajo interpretativo. Sin embargo, al proporcionar las armas, evitar los errores flagrantes, dar pistas, a veces se tiene la impresión de infringir un tabú metodológico ${ }^{46}$.

Se puede formular aquí una hipótesis sociológica más amplia, extraída del marco de numerosos trabajos de estudiantes durante la práctica de campo (entre 1988 y 1996) y de la dirección de memorias secundarias de DEA. Los estudiantes que se muestran menos reacios al tipo de postura exigida por la entrevista etnográfica (y también al modo de razonamiento sociológico) son aquellos que, durante su historia personal, han experimentado experiencias sociales opuestas, tanto en el mundo académico como en universos extraescolares. Solo se puede suscribir aquí a la idea de que la experiencia de un cambio de ambiente social por parte del entrevistador permite comprender mejor a las personas "del interior" ${ }^{\text {" }}$. Este punto es fundamental: todo el mundo no "ve" en la entrevista; el punto de vista sociológico no es compartido por todos. Aquellos que por otro lado tratan de transmitirlo se enfrentan en el campo a fuertes resistencias -que, durante la práctica, generan conflictos y tensiones entre estudiantes y formadores- por parte de los aprendices-etnógrafos que no pueden realmente escuchar las investigaciones, y prefieren volver a los esquemas teóricos explicativos a priori que han decidido adoptar cueste lo que cueste, sea cual fuere la forma de desmentido que pueda aportarles la situación de entrevista, sirviéndose de su cultura libresca como una especie de caparazón mental y moral que

46 Todos sabemos que los investigadores que se han abierto camino solos en campo, a menudo "tambaleando", en un entorno intelectual y disciplinario bastante hostil o indiferente, no siempre se han preocupado por transmitir un conocimiento que ha sido pacientemente acumulado, un saber que debieron reunir bajo su propio riesgo (científico) y con frecuencia contra otras corrientes más poderosas.

47 Pierre Bourdieu, Choses dites (París: Minuit, 1987) y la entrevista de Florence Weber con Gérard Noiriel: "Journal de terrain, journal de recherche et auto-analyse", Genèses 2, n. 1 (1990): 138-147. 
les permite "hacer" frente a la prueba o el veredicto que constituye el campo ${ }^{48}$. Si este tipo de aprendizaje en acción de la sociología es tan rico en información, lo que deja ver, de la manera más natural, son las diversas formas de resistencia a la sociología. Resistencia con respecto a este esfuerzo que consiste en analizar a los entrevistados como personas sociales, es decir, como individuos que tienen una historia compleja (historia familiar, escolar, profesional, conyugal o matrimonial, etc.) que conviene consultar. En todo caso, las historias singulares de los entrevistados no siempre interesan a los (futuros) sociólogos. ¿Se trata tan solo de una falta de curiosidad social, la cual se tiende a olvidar que es una de las condiciones de interés del sociólogo para la investigación de campo? o es la expresión de un malestar relacionado con que el desarrollo de una entrevista en profundidad requiere buscar aquello que perciben como propio de la esfera privada del entrevistado (y también de la suya...), lo que les puede parecer sin relación directa con el objeto de la investigación (el sociólogo se muestra entonces indiscreto, maleducado, incorrecto). Probablemente aún más, estas resistencias al trabajo etnográfico, acentuadas durante la prueba para la preparación de la entrevista en profundidad, se refieren no solo a la historia social y académica de los estudiantes sino también a la concepción que se hacen de la sociología. La resistencia a la investigación de campo, y especialmente a la entrevista etnográfica, cuenta con posibilidades de ser aún más fuerte que su concepción de la sociología como una ciencia nomológica, en busca de leyes de validez general, también de una ciencia no "psicológica”: concepción que se encuentra en las antípodas de aquella que da a conocer el trabajo meticuloso del etnógrafo, que puede parecer "beta” a quienes se consagran a requisitos intelectuales más elevados. La sociología que se presenta bajo la luz de la etnografía a veces puede dar la imagen de una disciplina "trivial" (que se permite consideraciones a partir de indicios tenues como entrevistas con personas singulares), engañando o defraudando así las expectativas intelectuales del aprendiz en la profesión que sueña con teorías que, si no son grandiosas, al menos son “sagaces”, pudiendo justificar su compromiso personal y profesional en el arriesgado camino de la sociología,

48 En efecto, este tipo de aprendizaje de práctica también es una prueba social y psicológica. Existen una vida grupal, unas rivalidades entre estudiantes (futuros competidores en el mercado de los apoyos económicos estatales y de las tesis), unas valoraciones sociales que hay que conquistar o que se corre el riesgo de perder; algunos estudiantes se "desconciertan", otros pierden su altivez teórica, las jerarquías escolares también pueden (temporalmente) alterarse. En la experiencia inmediata del periodo de prácticas (que también es una experiencia solo escolar), todo transcurre como si cada miembro del cuerpo de estudiantes debiera estar a la altura de la situación. Cada uno se está reasegurando constantemente acerca de la manera en que su investigación se lleva a cabo, en particular, en el momento de los intercambios informales entre mentores y docentes durante el regreso diario al campamento base (-Estuvo bien-, —él (o ella) fue amable-, -fue cool—, —nos invitó a comer, etc.-). 
tan dispersa y fraccionada desde un punto de vista institucional. No es raro ver a sujetos brillantes codeándose fuertemente con las realidades del campo y luego retomar los caminos más recorridos, más seguros, o más bien menos desestabilizadores, de la teoría sociológica o la sociología estadística.

\section{El trabajo material e interpretativo de la entrevista etnográfica}

Más allá del criterio del número o del carácter más o menos estructurado de las entrevistas, la verdadera línea divisoria en el trabajo con entrevistas parece ser la que separa a los sociólogos que hacen de ellas un simple medio para recoger información (u opiniones ${ }^{49}$ ) de aquellos que exigen o esperan más, que hacen de la entrevista un ejercicio de psicoanálisis social, un medio para la ejecución de un "socioanálisis". Esquemáticamente, esta línea divisoria tiende a coincidir con el desacuerdo que hay entre los que no han renunciado al principio de la noconciencia ${ }^{50}$ de los hechos sociales y los que optan por el principio de la transparencia del mundo social. Estas “opciones” teóricas no dejan de tener consecuencias sobre la forma de efectuar y, sobre todo, de "trabajar" las entrevistas. Específicamente veremos que ciertas operaciones, percibidas o definidas la mayoría de las veces como puramente técnicas, pueden ser mucho más que eso, pues

49 Abordar únicamente "representaciones" u "opiniones", es decir, un "discurso", es también evitar cuestionarse sobre los determinantes sociales "objetivos" de esos discursos, como el origen social, la trayectoria escolar, etc. Nos sorprende la tonalidad psicologizante y casi moralizante de las recomendaciones: hay que mostrarle al entrevistado que lo consideramos una persona en quien nos interesamos en su totalidad. La entrevista implicaría un tipo de intercambio afectivo fundamentado en el respeto mutuo, incluso si la relación es totalmente asimétrica. ¿No podemos ver en esta concepción de la entrevista la proyección metodológica de un normativismo político propio de la ciencia política tradicional, como ciencia electoral (valorización de la igualdad formal de los ciudadanos), en el contexto en que la entrevista semiestructurada escenifica, en un tipo de humanismo metodológico, ciudadanos ilustrados e iguales? No obstante, lo que un investigador nota de entrada en la situación de entrevista, a condición de que él no esté obnubilado con la idea de recoger "opiniones", es que son personas "de carne y hueso", que cambian en el contexto de su vida privada (su vivienda, su "interior"), que se encuentran directamente confrontadas con la prueba social de hablar en público. Al final, podemos cuestionarnos si la entrevista no estructurada no hace sino expresar, en el plano metodológico, esta especie de ideal republicano del ciudadano ilustrado (aquel que vota, que no se abstiene, etc.). ¿No podríamos formular la hipótesis, a partir de las similitudes de las concepciones de los actores sociales, de que la entrevista semiestructurada, del tipo "ciencias políticas", es a la entrevista etnográfica lo que el "sondeo" es a un cuestionario sociológico bien construido? (París: Mouton, 1968). 
no dejan de implicar hipótesis de investigación y actos de interpretación de parte del sociólogo.

\section{Reunir las condiciones para el buen desarrollo de la entrevista}

Acá identificamos tres de esas condiciones que pueden parecer evidentes pero que siempre es mejor explicitar por completo: la elección de los entrevistados, la negociación del lugar y la duración de la entrevista, y lo que impulsa la palabra del entrevistado.

Todo investigador de campo sabe bien que uno de los momentos más delicados de manejar en la investigación es cuando se pasa del estado de la "discusión informal” a la entrevista grabada, solemne. Siempre corremos el riesgo en ese momento de "romper” la relación de investigación, de hacer sentir incómodos a los entrevistados. En campo, el investigador debe hacer frecuentemente elecciones, él no puede (ni debe) entrevistar a todo el mundo; entonces, conducirá a lo largo de su investigación un tipo de "trabajo" de localización de posibles entrevistados, específicamente, a partir de las informaciones recogidas con sus informantes o durante discusiones informales. A la vez, debe evitar a los impertinentes - aquellos que él presiente que serán “charlatanes”, que no harán avanzar la investigación y que, incluso, la frenarán-y saber atraer a aquellos que él "supone” que serán "buenos” entrevistados. Esta selección previa de las personas a entrevistar seguirá mejorando a medida que avance la investigación y que su problemática se haya consolidado. Una vez aceptado el principio de la entrevista, es importante poder hablar en un lugar tranquilo, tener el tiempo suficiente, poder grabar.

Realizar una entrevista etnográfica jamás es un gesto anodino. En el momento de reunirse, el investigador siempre siente un poco de tensión: él jamás sabe exactamente cómo se va a desarrollar el encuentro, allí puede haber imprevistos, malentendidos, "problemas”. Para asegurar las mejores condiciones materiales del encuentro, siempre hay que negociar con los entrevistados el lugar y la duración de la entrevista. Por ejemplo, disponer de un periodo suficientemente largo (al menos dos horas) le permite al investigador conducir la entrevista con toda tranquilidad, sin tener que apresurar las cosas o "presionar" a su interlocutor; además, la fijación de una duración mínima con frecuencia significa, ante los ojos del entrevistado, que este intercambio es un trabajo "serio". La realización de la entrevista en un tiempo largo permite que se desarrolle, no según un orden predeterminado, sino obedeciendo a un cierto número de fases: 
la primera corresponde a un tipo de ronda de observación entre los interlocutores, que les permite "conocerse”, "romper el hielo" y, a veces, juzgarse. Después, una vez definida la situación de entrevista, esta toma un ritmo de crucero, pero puede presentar cambios de ángulo, bifurcaciones (un tema nuevo que merezca ser profundizado); cuando la entrevista llega a su fin — generalmente, los últimos momentos son los más ricos, los más "personales”- todo sucede como si el entrevistado, que siente que se acerca el fin del intercambio, tuviera la necesidad de hacer confidencias, de revelar en el último momento cosas que después hubiera lamentado no haber dicho. Hacer que la entrevista dure le permite al sociólogo explorar diferentes pistas y contribuye a bajar progresivamente el nivel de censura que tiene todo entrevistado; este, confiado, empieza a vigilarse menos, a bajar la guardia (para perseguir la metáfora del combate de boxeo). Para comprender esta virtud de la entrevista en profundidad, hay que examinar más detalladamente la naturaleza de la relación entre investigador/investigado.

También, podemos cuestionarnos por qué una entrevista sociológica "camina", en el sentido de que se produce un intercambio "fuerte" de palabras en una interacción —en ocasiones muy larga y casi siempre única- entre dos personas que al comienzo se desconocen. No todo es una cuestión de conocimiento y de destreza del sociólogo (incluso si eso cuenta). En realidad, el motivo de la entrevista se encuentra menos en el fenómeno intersubjetivo del intercambio que en la configuración objetiva de la situación; está bien porque a fin de cuentas la entrevista es una situación inédita de la vida social: un largo encuentro (grabado) entre dos desconocidos, y también una situación que tiene buenas oportunidades de seguir siendo única. El investigador, por su posición exterior en la red social de los entrevistados, está — por definición estatutaria- alejado de las cuestiones sociales de la competencia y la rivalidad, fuera del juego local. Ya que él es fundamentalmente este "extranjero", el entrevistado siente que puede abrirse con él, revelándole progresivamente aspectos de su propia existencia que les habrían parecido muy "privados" a sus allegados ${ }^{51}$. Es esta posición (temporal) de extranjería, desventaja inicial para comenzar la relación, la que después se puede — si la entrevista está bien dirigida — transformar en el motor de la palabra del entrevistado.

51 Cuántas veces el investigador oye decir después de una entrevista: "Jamás hubiera pensado decir tanto", "eso solamente se lo he dicho a usted". 


\section{La transcripción de las entrevistas: objeto de un verdadero trabajo interpretativo}

Mientras que la calidad de la transcripción es esencial para el análisis detallado de una entrevista, pues puede enriquecerla o empobrecerla considerablemente, constatamos que esta fase, muy práctica, del trabajo con entrevistas es raramente abordada como asunto de reflexión o como tema de un saber pedagógico. Esta fase parece darse por sentada y parece que debe ser el objeto de un simple trabajo material de transcripción de las grabaciones - trabajo lento, aparentemente fastidioso y puramente técnico- que muchas veces se le encarga a "pequeñas manos", a las que les damos simplemente algunas instrucciones de transcripción. Para todo el mundo es muy claro que la parte noble del trabajo comienza en el momento de la interpretación, una vez que el investigador dispone del "texto" (la entrevista transcrita) bajo sus ojos ${ }^{52}$.

Sin embargo, es necesario resaltar la importancia de una transcripción integral de las entrevistas sobre las cuales hemos decidido trabajar de manera intensiva; esta es la condición necesaria para percibir y analizar la "dinámica" de la entrevista. En efecto, transcribir una entrevista grabada es traducir el habla en texto, es realizar esta fase fundamental que consiste en pasar de lo oral a lo escrito, pero también es correr el riesgo de perder lo que hace la especificidad y la riqueza del habla ${ }^{53}$ : no son solo las palabras, el vocabulario, las formas sintácticas, sino también el tono, el timbre, el ritmo de la voz, sus diferentes entonaciones y modulaciones, los cambios de ritmo y de ánimo; todos los sutiles matices de las emociones que pasan a través de la voz, lo que luego permite adivinar o reconstituir los gestos, las mímicas del actor. Escuchando el habla de esta manera, el sociólogo puede aprehender las características más corporales, las más personales y, al mismo tiempo, las más sociales de la persona. Son estas propiedades las que mejor definen la tonalidad de una entrevista. Entonces, una entrevista sociológica es más rica e interpretable cuando su transcripción respeta los

52 El hecho de no transcribir por sí mismo la totalidad o una parte de sus entrevistas, y de tener a su disposición cientos de páginas de entrevistas transcritas de una manera más o menos minuciosa, conduce inevitablemente a comparar "discursos". Esto refuerza la impresionante ambigüedad que reina alrededor de la expresión del "discurso" cuando hablamos de una entrevista, ya que - al utilizar la expresión de "discurso" - contribuimos profundamente a negar el acto del habla, a traducir esas imágenes y sonidos en "texto" puro.

Para una discusión sobre la cuestión del grado de "literalidad" de la transcripción, cf. la discusión entre Bernard Lahire y Stéphane Beaud en "Quelques observations à propos du texte de Bernard Lahire", Critiques Sociales 8, n. 9 (1996): 102-107. 
silencios, resalta las dudas y los retrasos, registra los cambios en la voz y señala las diferencias de tono, anota los gestos y mímicas que acompañan las palabras.

Durante el tratamiento de mis propias entrevistas medí experimentalmente el aporte inestimable del trabajo de transcripción, al comparar la interpretación que podía hacer de las entrevistas que había transcrito personalmente y la interpretación, más incierta y aleatoria, de las que había hecho transcribir. De inmediato, las primeras parecen ser más ricas, más interpretables, el sociólogo las puede trabajar con mucha más sensibilidad. Es en el momento de la transcripción, escuchando y reescuchando la grabación, impregnándose "auditivamente” de la entrevista, reviviendo de alguna manera la escena, pero esta vez estando libre de la presión de la interacción (conducir la entrevista, hacer durar el intercambio), que el sociólogo tiene más posibilidades de hacer el mejor trabajo interpretativo. Es entonces cuando él se propone algunas hipótesis de investigación, que elabora, en el secreto de su pequeño laboratorio personal que constituye la transcripción, nuevas hipótesis de trabajo, que explora libremente nuevas pistas, que construye con algo de temeridad el comienzo de una interpretación que va a afinar o a corregir a medida que vaya avanzando la transcripción. Siempre es cuando escuchamos la "grabación" que redescubrimos pasajes de la entrevista que casi habíamos olvidado o a los cuales no les habíamos prestado verdadera atención en el momento ${ }^{54}$. Entonces, tomando distancia, estos pasajes adquieren un mayor relieve y, en ocasiones, vienen a adquirir otro significado, con lo cual resultan ubicados algunas veces en el centro del análisis. El interés esencial de escuchar atentamente, o por lo menos de reescuchar las grabaciones, reside en esta posibilidad de corregir nuestras "primeras impresiones", de regresar a nuestras primeras interpretaciones (anotadas "en caliente” y de manera rápida en el diario de campo) y de efectuar una especie de control de las empatías (o antipatías) del sociólogo. Si él "escucha” de una manera diferente durante la transcripción, es porque no está más en la situación de cara a cara en la que generalmente él, presa de la interacción, escucha medias palabras, cree comprender más de lo que en realidad comprende. Es en el momento de la transcripción que evaluamos el alcance de los malentendidos y de los falsos acuerdos que, en ocasiones, han sustentado la entrevista y, muchas veces, es ese "ruido" en

54 Como lo dice Freud a propósito del tratamiento analítico: "No olvidemos que el significado de las cosas escuchadas generalmente no se revela sino hasta más tarde". Sigmund Freud, La technique psychanalytique (París: PUF, 1953), 12. 
la comunicación entre investigador/investigado el que conduce a repetir ciertas preguntas que van en contra de las primeras hipótesis planteadas ${ }^{55}$.

Durante dos entrevistas realizadas con tres días de intervalo a una estudiante de último año en el antiguo liceo burgués de la ciudad, que era hija de un obrero de la fábrica, me di cuenta en retrospectiva, al transcribir las grabaciones, de que había estado literalmente obsesionado por el deseo de hacerla hablar como a los otros estudiantes (niños de las barriadas, hijos de obreros especializados, generalmente inmigrantes) con quienes yo ya había sostenido una larga serie de entrevistas en profundidad. De una manera inconsciente, la hacía soportar unas preguntas que en ese momento yo pensaba que estaban bien afinadas. Así, dejándome guiar por la rutina del trabajo y reproduciendo un tipo de guía mental de entrevista, después me di cuenta de que había sido ciego a otras realidades que me hubieran debido alertar en el momento de la entrevista: en particular, el hecho de que Lila no era la hija de un "simple obrero", sino la hija de un jefe de equipo cuya familia venía de instalarse en un chalet, dos aspectos que redescubrí durante la transcripción. La escucha de la grabación no ha dejado de interrogarme (he pasado allí un tiempo considerable), ya que mis preguntas suscitaban de parte de Lila respuestas cortas y secas, silencios molestos, de vergüenza, sonrisas o risas traviesas, etc. Buscando esclarecer lo que parecía una interacción perdida (todo lo que hace una "mala" entrevista desde un punto de vista técnico), debí rehacer todo un trabajo para comprender el malentendido que se había establecido entre Lila y yo alrededor de esta entrevista, que me obligaba a plantear sin cesar la pregunta acerca del tipo de relación que había establecido con ella, a relatar con precisión las circunstancias del encuentro, a examinar las expectativas que yo había suscitado en ella. Solo el análisis detallado de la relación social entre el investigador y el entrevistado permite aclarar la divergencia entre las expectativas de ambos y explicar los malentendidos permanentes que llenan la entrevista; al final, contra toda fetichización del textoentrevista, esta es la relación que prioritariamente debe ser el objeto del trabajo interpretativo.

Estos “descubrimientos” de la transcripción resultan ser momentos agradables de la investigación (momentos que deberían poder ser anotados de manera sistemática en un diario de investigación) donde vemos aparecer repentinamente, de este trabajo de transcripción en apariencia ingrato, otro sentido social de las palabras del entrevistado que contribuyen a darle otro giro a la investigación. En este sentido, podemos decir que la escucha atenta de las grabaciones es

También es por esto que a los estudiantes se les da la instrucción de grabar sus entrevistas, para poder retrabajar a partir de las grabaciones. 
una forma impresionante de analizar y acelerar hipótesis de trabajo durante la investigación de campo.

\section{La atención a las palabras, a los silencios $y$ a lo no dicho}

Una vez que su (sus) entrevista(s) esté(n) transcrita(s) con fidelidad, ¿cómo comienza el sociólogo-investigador a interpretar esa masa de materiales? Por supuesto, está el problema de la comparación y de recurrir al principio de variación de las diferencias sociales que parecen progresivamente pertinentes (incluso si son mínimas): por ejemplo, confrontando de modo sistemático los puntos de vista sobre la formación de los obreros pertenecientes a un mismo taller según sus modos de arraigo obrero, sus cualidades profesionales, su trayectoria escolar, lo que esperan de su futuro, sus modos de inscripción en las redes militantes, su estado matrimonial, limitaciones presupuestales y familiares ${ }^{56}$, etc.

Pero una de las herramientas privilegiadas para la interpretación consiste en el análisis de las palabras “nativas”, las palabras de los diferentes entornos (profesional, social, geográfico, familiar) a los cuales pertenece el entrevistado, que suponen una serie de palabras sociales que sintetizan una práctica, una existencia, una percepción del mundo social. Su eficacia (para el sociólogo) reside en que dicen a su manera - simple, gráfica, cotidiana- categorías "nativas” de clasificación y juicio que podemos confrontar con los modos de clasificación social más generales y abstractos. Este es, por ejemplo, el caso de las palabras de fábrica (aduladores, basura, huelguista) o de las palabras de los ejecutivos (disponibilidad, trabajo en equipo). Trabajar de manera atenta el material permite darle de nuevo una gran importancia al lenguaje nativo, a la capacidad de cualquier entrevistado de encontrar las palabras justas o de inventar en el momento expresiones que tienen la virtud de condensar o de decir la verdad social de una situación. Como el director de un colegio de Zonas de Educación Prioritaria (ZEP) que, para mencionar la división social del establecimiento que se sitúa en una colina (donde se ubica un barrio de viviendas de interés social), habla del “juicio final” a propósito del momento de la salida del colegio: los “elegidos” siguen hacia la derecha para

56 Esto fue lo que intentamos hacer en nuestra investigación. Cf. tomo 1 de Stéphane Beaud y Michel Pialoux, Ouvriers de Sochaux: l'affaiblissement d'un groupe. Hantise de l'exclusion et rêve de formation (París: Laboratoire de Sciences Sociales, Centre de Sociologie de l'Éducation et de la Culture, 1993). Informe de investigación (n. $\left.{ }^{\circ} 400-490\right)$, para la Mision de Investigación Experimental del Ministerio del Trabajo (MIRE, Mission Recherche Expérimentation du Ministère du Travail). 
regresar a las casas del valle y los "condenados" se van hacia la izquierda para volver a su vivienda de interés social. No se trata de realizar un análisis lingüístico - los sociolingüistas lo hacen muy bien- sino de hacer un trabajo (durante la entrevista y la interpretación) de interconexión entre esas palabras y la posición social objetiva de las personas consideradas y de los grupos a los cuales pertenecen. Como lo recuerda James Spradley, el etnógrafo no deja de realizar un trabajo de traducción entre el lenguaje nativo y el lenguaje ordinario ${ }^{57}$.

El sociólogo también le va a prestar una atención particular a todo lo que en una entrevista esté dicho a media palabra o lo que aparezca entre líneas, a las dudas, a las contradicciones más o menos aceptadas o, aún más, a las negaciones o silencios repetidos. El sociólogo se esfuerza en sentir los momentos en los que la palabra duda o balbucea, cuando el entrevistado se tensiona, "se cierra", porque estamos tocando aspectos esenciales de su existencia social. Son estas zonas de "resistencia” que el investigador - "experimentado" y no atemorizado de mirar estos rincones de la personalidad social- siente inmediatamente, que son los más interesantes de "trabajar", de analizar en el momento y de comentar. En este sentido, es fuerte la similitud entre el ejercicio y el trabajo analítico. Este ejercicio interpretativo puede, por cierto, aplicarse a situaciones de observación o a un trabajo retrospectivo sobre las escenas vividas ${ }^{58}$. Entonces, podemos considerar que una entrevista es tan interesante por lo que dice como por lo que esconde o lo que dice a media palabra.

Para ilustrar la importancia de los silencios y de lo no dicho en las entrevistas, aquí presento provisoriamente algunos ejemplos tomados de mi trabajo de campo con estudiantes de secundaria, hijos de obreros de Sochaux-Montbéliard ${ }^{59}$.

Para los hijos de los obreros inmigrantes especializados que viven en los bloques (las viviendas de interés social de la región), la pregunta sobre el trabajo del padre en la fábrica suscita malestar y resistencia. Aunque sus padres sean obreros especializados o cualificados, ellos responden con frases breves y lacónicas o con expresiones estereotipadas. El investigador debe insistirles para poder "arrancarles" algunas palabras; pronto, él siente que hacerlo sería inapropiado. Entonces puede interpretar la actitud desganada o las muecas de los

57 James Spradley, The Ethnographic Interview (Nueva York: Holt, Rinehart y Winston, 1979).

58 En particular, pensamos en los excelentes "Carnets de socio-analyse" de Yvette Desault. Cf. Yvette Delsaut, "L'inforjetable", Actes de la Recherche en Sciences Sociales 74, n. 1 (1988): 83-88, DOI: 10.3406/arss.1988.2439; Yvette Delsaut, "La photo de classe", Actes de la Recherche en Sciences Sociales 75, n. $^{\circ}$ (1988): 83-96.

59 Cf. capítulo VII de mi tesis de doctorado en sociología "La démocratisation du lycée et ses enjeux", en "L'usine, l'école et le quartier. Itinéraires scolaires et avenir professionel des enfants d'ouvriers de Sochaux-Montbéliard" (tesis de doctorado, Ehess, 1995). 
entrevistados ante sus preguntas como una invitación educada a finalizar este punto de la discusión. Pero, progresivamente, la pregunta central de mi trabajo parecía ser sobre la transmisión de la herencia en las familias obreras o, más bien, sobre el quiebre de la transmisión entre la generación de los padres y de los hijos. Sin embargo, la interrogación directa sobre este tema es torpe, forzosamente acusadora e, incluso, culpabilizante, ya que obliga a los entrevistados a explicitar la toma de distancia con el padre, la ruptura progresiva con el universo familiar que, para ser habitable o soportable, con frecuencia es vivido en lo no dicho, en lo implícito y en el malestar recíproco. Regresaban a la boca de los estudiantes entrevistados las mismas expresiones, cargadas afectivamente, y todas manifestaban una impresión de morbosidad y desprecio ("siempre odié eso", “es sucio”, “asqueroso”...). El trabajo del padre y, en general, las condiciones de vida de la familia, el dinero - como otros tantos temas que jamás abordaba de manera directa en la entrevista - no parecen pertenecer al orden de lo que se puede decir. Tenemos la impresión de que allí habría muchas cosas que decir y que habría que acumular anécdotas, detalles que permitirían penetrar la intimidad del espacio familiar. Necesariamente, esto sería hablar del cansancio y del desgaste físico del padre, de la reducción progresiva de sus fuerzas, también mencionar los miedos en la fábrica (como ser trasladado de puesto de trabajo, llegar a un sector más “duro”, ser despedido un día...). En lugar de esta crónica imposible de mantener, los estudiantes entrevistados responden con suspiros, frases inconclusas, gestos que marcan la impotencia y la resignación; el trabajo de sus padres en la fábrica es mencionado más bien con compasión y lástima. En este silencio de los hijos sobre el trabajo del padre ${ }^{60}$, podemos ver también la preocupación por no ceder a la tentación de realizar una descripción miserabilista de su familia (de "faire du Zola" ${ }^{1}$, como me dijo uno de ellos). En una entrevista, el silencio puede ser la única manera de expresar el rechazo que sienten hacia la herencia obrera de sus padres. El silencio manifiesta entonces el "respeto" que los hijos les deben forzosamente a ellos y hace parte de una especie de convención tácita que rige las relaciones intergeneracionales en la familia. El silencio que enfrenta el investigador es, por lo tanto, la única respuesta posible que ellos pueden dar (de una forma cortés) ${ }^{62}$. Los estudiantes hacen parte de un

\footnotetext{
60 ¿Cómo hablar de la cultura del trabajo obrero especializado que se presenta como una "cultura de la carencia" (falta de tiempo, de dinero, de esperanza, de ausencia de futuro)?

61 La expresión francesa faire du Zola se refiere a una descripción de la miseria humana. [N. de la E.]. campesinos (como los campesinos sicilianos) era el único medio de enfrentar el universo de
} 
mecanismo dual de defensa: por un lado, se protegen a sí mismos, defendiendo su futuro, dándose un margen de maniobra que les permita relacionarse con un grupo que tenga aspiraciones diferentes a las del grupo obrero, para poder pensarse de una manera diferente a la del hijo de un obrero que está consagrado a un destino social de obrero. Por otro lado, defender "a pesar de todo" la estima de sus padres, el respeto a su trabajo duro e ingrato, a este "trabajo de esclavo" (expresión oída muchas veces en entrevistas o en otros lugares). La situación de entrevista resulta aquí particularmente importante. Les pregunto sobre su escolaridad pasada y presente, en tanto "estudiantes de secundaria", de manera que las preguntas sobre los padres, sobre el trabajo del padre, pueden parecerles que ya han sido desplazadas o que ya no son el centro ${ }^{63}$. Hablar del trabajo del padre en este momento de sus carreras escolares es, por definición, contradictorio, es conciliar un pasado que muere y un futuro que va en otro sentido, es permanecer fiel al padre "privado" y negar al padre "profesional", es respetar la autoridad del padre en la familia y “criticar” su sumisión a la fábrica. Es también incrementar las experiencias sociales vividas en el colegio que les han hecho interiorizar la posición dominada de sus padres.

\section{Como joven estudiante, ¿cómo hablar de su padre obrero e inmigrante?}

Para mostrar esta dificultad de hablar sobre el trabajo del padre, presento aquí algunos extractos de una larga entrevista con Mehmet, quien en el momento en que lo conocí era estudiante de primer año de Licenciatura en Administración Económica y Social (AES). Hijo de un inmigrante turco, vino a Francia a los cuatro años. En la mitad de su último año de secundaria, él planeaba inscribirse en AES para convertirse más tarde en funcionario ("es genial") o, para usar sus propios términos, funcionario-profe. Esta era su oportunidad de señalar las ventajas de esta profesión e, inevitablemente, de compararla con el trabajo de su padre en la fábrica:

\section{— ¿De dónde vino esta idea de ser un funcionario?}

-Esto, a mí me encantaba lo que hacían los profes... ifuncionario-profe!... Los profes, ellos eran relajados, tenían buenas vacaciones y además yo tenía amigos que habían tenido padres profes. También ellos que-

violencia social del que eran prisioneros. Este silencio contrasta con la necesidad de liberación por medio de la palabra que tienen estos jóvenes obreros que hablan de la fábrica, del trabajo obrero, del ambiente en los talleres en términos muy físicos, desde el punto de vista de una experiencia vivida en sus cuerpos y en sus mentes.

63 A propósito, son los estudiantes escolarmente más aculturados quienes tienen mayor dificultad en mencionar esta cuestión del trabajo, mientras que aquellos que se mantienen lejanos de la cultura escolar pueden hablar de ello más libremente, ya que la perspectiva de trabajar un día en la fábrica (no como obreros, sino como jefes o directivos) no les es completamente extraña. 
rían ser profes, quizás fue eso lo que también me influenció... [risas]... Entonces él [su amigo] me dijo: “Sí, está bien, le pagan diez mil francos por mes”, bueno, hay vacaciones, dos meses pagos, bueno, eso hace... cuando yo veo a mi papá trabajando [duda en decir la palabra, tono más sarcástico]... así, allá [no menciona la fábrica]

-Tu papá trabaja en la fábrica...

-Sí, él trabaja en la fábrica [lo dice muy rápidamente, como para evitar otra pregunta]... yo me decía, bueno, ¡es mucho mejor!... Y, por lo menos, si uno es funcionario, no tiene la angustia de ser despedido... Uno no tiene la angustia... eso dependerá de la coyuntura económica [pequeña risa].

- ¿Y esta idea de ser funcionario la tienes desde el último año o desde antes? ¿Cuando tú estabas en tercero de bachillerato qué querías hacer?

— ¿Cuando estaba en tercero? Esto, siempre es así, yo siempre quise hacer eso. Cuando era niño, quería ser piloto, cosas así, pero... [risas] no hay que aspirar a tanto, por lo menos hay que ser realista...

— ¿Y cuándo te pareció importante el hecho de no ser despedido?... ¿Tu padre habla de eso?

—Esto, yo veo lo que... cada vez que hay un plan social allá, yo veo cómo son [rectifica]. Veo cómo es [duda de nuevo]... Cada vez que hay un plan social, ellos son... [no encuentra la palabra justa o no se atreve a decirla]. Que sea mi tío que también trabaja allá, que sea él, ellos son [suspiro] ¡Ellos tienen mucho miedo!...

— ¿Y ustedes hablan de eso un poco? ¿Tu padre te cuenta algo?

-Sí... él me dice: “Es mucho, ellos nos hacen trabajar mucho...”, todo eso para repugnarles... para que ellos regresen a su país o para que dejen de trabajar, es todo... [silencio].

- ¿Y tu padre trabaja en qué sector de la fábrica?

—En pintura, creo... en pintura, sí... [silencio].

-Y tú jamás has querido trabajar...

-Ya trabajé en su cosa... sí, ya trabajé, en decapado...

— ¿Y te parece duro?

—Este, no... [risas] ¡no es un regalo! Pero nosotros [los "escolares"] no hemos hecho el mismo trabajo... estábamos limpiando la pintura. No sé lo que él hacía, lo que él hace especialmente... pero de todas maneras la pintura no es... ¡no es un regalo! Con el polvo que uno tiene en... en todo lado... y después hay un momento en el que él se hacía todo el tiempo análisis de sangre, todo eso para... [...].

-Y para volver a esta cuestión del colegio, tú querías convertirte en funcionario, pero en funcionario-profe, no había otras...

—... [Cortándome] Sí, funcionario... De todas maneras funcionario, es... 
Yo quería un trabajo genial... bueno, no quiero decir que ser profe es suave [mirándome, dándose cuenta de su “error”], ipero por lo menos es más suave que los otros trabajos, ¿no?! [silencio].

-Sí, es más suave que trabajar en la fábrica...

—Es más suave que los otros trabajos... [silencio].

-Y durante tu último año, también había...

- [Cortando] Sí, había cosas... BTS, todo eso, eso me tentó... pero después me dije "los $\mathrm{BTS}^{64}$ son muy importantes, pero...” [silencio]... hay que trabajar como un "loco” [risas]. E, incluso, después no es seguro tener un trabajo. Mientras que como funcionario, esto, pasas concursos, de todas formas es difícil ser contratado, pero después de que eres contratado, estás tranquilo... funcionario-policía también... policía... eso es... pero la vista, eso asusta también, como soy miope.

Lo más sorprendente son las dudas en el momento de nombrar las cosas, de llamar a la fábrica por su nombre (una “cosa”), también esas frases iniciadas y jamás terminadas, los diferentes movimientos verbales para intentar encontrar las palabras precisas, todo lo cual constituye una serie de medidas que utiliza el hijo para tratar con consideración a su padre. Mientras que durante la entrevista los conflictos entre el padre y el hijo (a propósito de su futuro, de los “papeles franceses” ${ }^{65}$ que el hijo quiere, del uso del dinero, de las distracciones, etc.) son más o menos aceptados por Mehmet - por lo menos él habla de eso-, cuando se le pide hablar del trabajo de su padre, se encuentra como paralizado por la idea de hacerle daño, sea al faltarle compasión o "respeto" o al no saber hacerle justicia a su manera. Frente al miedo que sienten los padres obreros en la fábrica — padres débiles física y socialmente-, para Mehmet lo que está en juego es ser un hijo "levantado", cuyo objetivo es la conquista de una seguridad laboral. La expresión "funcionarioprofe" o "funcionario policía” (de forma que no deba temerles más a los controles policiales, de los que él es una víctima regular), mediante la cual el estatus jurídico protector ("funcionario") termina intensificando la designación protectora de la profesión particular (“profe”), expresa de una manera justa el miedo a la inseguridad material y moral en la cual su padre, en particular, y los obreros especializados de la fábrica, en general, viven constantemente. formación técnica luego del bachillerato. [Nota de la E.]. 
Los usos diferenciados de la entrevista en ciencias sociales sostienen una relación estrecha con la legitimidad de los modos de investigación. Si a lo largo de este texto hemos defendido la entrevista etnográfica, ha sido ignorando temporalmente el hecho de que el dominio de la investigación "cualitativa" (fundamentada principalmente en entrevistas y observaciones) no es homogéneo: las normas de trabajo no son claras y muy rara vez son explicitadas. Muy a menudo, el uso intensivo de entrevistas (cualquiera que sean su naturaleza y sus características) o el solo hecho de haber ido a campo son suficientes para promover y bautizar el trabajo realizado como una "investigación de campo”. ¿Uno de los principales obstáculos que encuentra el trabajo etnográfico en Francia en su búsqueda de reconocimiento de legitimidad científica no reside justo en el uso generalmente abusivo que se hace de esa etiqueta? Las limitaciones propias del trabajo etnográfico ofrecen una especie de recompensa a los que hacen lo que podríamos llamar "falso trabajo de campo"; es decir, los que a pesar de utilizar un mínimo de técnicas de investigación etnográfica —al privilegiar casi únicamente las entrevistas y al restituir de una manera muy sucinta las condiciones sociales (precisas) en las que se recogen - y cuya presencia en campo es, casi siempre, cercana a la de los periodistas (rapidez de la estancia en campo) o al trabajo delegado (trabajo de investigación efectuado por sus estudiantes con base en instrucciones). Los resultados de una investigación cuya fase de trabajo de campo es corta, y cuyas diferentes etapas del trabajo de recolección e interpretación de información son evitadas, son rápidamente publicados. Podríamos decir aquí que la ley de Gresham se aplica perfectamente - "la mala moneda (investigación) desplaza a la buena”-, por lo cual los etnógrafos, quienes pagan el precio durante la entrada a campo y la aceptación por el entorno investigado, siempre estarán atrasados, o más bien en desfase, en relación con la demanda social de resultados "sociológicos", definidos así por los medios (la "crisis de los suburbios”, la "exclusión”, la "crisis de la escuela”, los “problemas de los inmigrantes”, la "crisis de la juventud", la "crisis de la política", etc.), incapaces de producir estas pseudo-"primicias" que los profesionales de la información esperan de los "sociólogos" ${ }^{\prime 6}$. Dicho de otra manera, en un contexto de competencia intelectual determinado cada vez más por la rapidez de las publicaciones y donde a los sociólogos se les pide cada vez más dar su punto de vista sobre todo, sin importar

66 Podemos tomar el ejemplo de los "suburbios" que ven prosperar investigaciones mal construidas, intervenciones rápidas de personas que entrevistan "todo lo que se mueve" en campo. Progresivamente asimilados como "simples" periodistas, que además le hacen frente a un número creciente de consultores y expertos en développement social des quartiers (DSQ) [desarrollo social de los barrios], cada vez más los sociólogos experimentan dificultades para entrar en campos como los "barrios" o, en todo caso, para poder ser aceptados allí. 
de qué, podemos decir que el verdadero trabajo de campo no es, en este sentido, rentable, incluso si puede serlo a largo plazo (por la “ciencia social”).

Traducido por

John Edward Sánchez Díaz

Especialista en traducción de la Universidad del Rosario jedsanz@hotmail.com

María Paula Hernández Antropóloga, Universidad del Rosario mariapaulahdz@gmail.com 